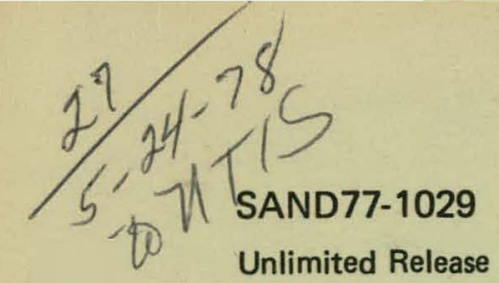

\title{
3151
}

\section{Description, Operation, and Diagnostic Routines for the Adaptive Intrusion Data System}




\section{DISCLAIMER}

This report was prepared as an account of work sponsored by an agency of the United States Government. Neither the United States Government nor any agency Thereof, nor any of their employees, makes any warranty, express or implied, or assumes any legal liability or responsibility for the accuracy, completeness, or usefulness of any information, apparatus, product, or process disclosed, or represents that its use would not infringe privately owned rights. Reference herein to any specific commercial product, process, or service by trade name, trademark, manufacturer, or otherwise does not necessarily constitute or imply its endorsement, recommendation, or favoring by the United States Government or any agency thereof. The views and opinions of authors expressed herein do not necessarily state or reflect those of the United States Government or any agency thereof. 


\section{DISCLAIMER}

Portions of this document may be illegible in electronic image products. Images are produced from the best available original document. 
Issued by Sandia Laboratories, operated for the United States Department of Energy by Sandia Corporation.

\section{NOTICE}

This report was prepared as an account of work sponsored by the United States Government. Neither the United States nor the United States Department of Energy, nor any of their employees, nor any of their contractors, subcontractors, or their employees, makes any warranty, express or implied, or assumes any legal liability or responsibility for the accuracy, completeness or usefulness of any information, apparatus, product or process disclosed, or represents that its use would not infringe privately owned rights. 


\section{PAGES 1 to 2 WERE INTENTIONALLY LEFT BLANK}


SAND77-1029

Unlimited Release

Printed March 1878

\section{DESCRIPTION, OPERATION, AND DIAGNOSTIC ROUTINES FOR THE ADAPTIVE INTRUSION DATA SYSTEM}

Norman E. Corlis

Telemetry Development Division 9421

Charles S. J̦ohnson

System Studiès \& Engineering Division 1754

Sandia Laboratories

Albuquerque, NM 87115

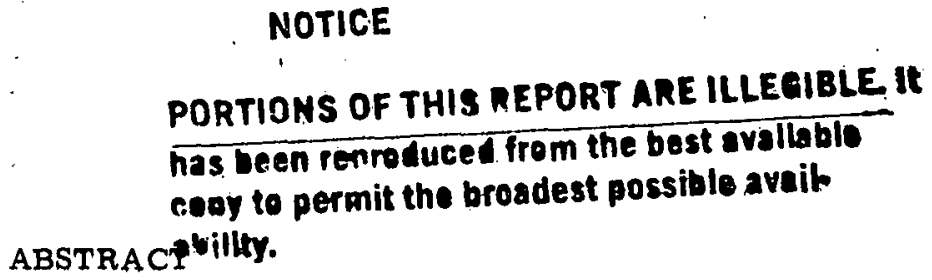

An Adaptive Intrusion Data System (AIDS) was developed to collect data from intrusion alarm sensors as part of an evaluation system to improve sensor performance. AIDS is a unlque digital data compression, storage, and formatting system. It also incorporates a capability for video selection and recording for assessment of the sensors monitored by the system. The system is software reprogrammable to numerous configurations that may be utilized for the collection of environmental, bi-metal, analog, and video data, This manual covers the procedures for operating AIDS. Inatmotiono are given to guide the operator in software programming and control option selections required to program AIDS for data collection, Software diagnostic programs are included in this manual as a method of isolating system problems.

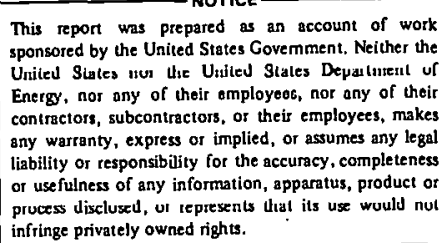


$\begin{array}{lll}1.0 & \text { Introduction } & 7\end{array}$

2. 0 System Description $\quad$ - 10

2. 1 Data Format $r$

$\begin{array}{lll}3.0 & \text { Turn-on Procedures } & 14\end{array}$

3.1 Time Code Generator $\quad$ * $\quad 14$

3.2 Video Subsystem $\quad: \quad 14$

3. 3 Alarm Monitoring Chassis $\quad \cdot 16$

3.4 Analog Signal Conditloner/Interface $\quad$. 16

3. 5 Environmental Data Display 16

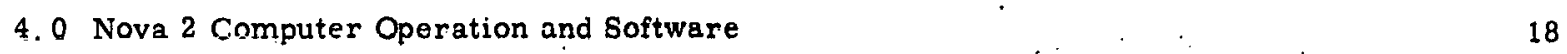

4.1 Software Description $\quad$. . . . . . 18

4.2 Program Tape Loading . . . $\quad 23$

4.3 Program Load Sequence $\quad$. $\quad: \quad$ : 23

5. 0 Program Execution and Operation: ALARM Program Loading 25

5.1 MCP/Header $\quad \cdot \quad 25$

$\begin{array}{ll}5.2 \text { R-Run } & 31\end{array}$

5.2 .1 Option $1 \quad 34$

5.2 .2 Option $2 \quad \cdots \quad 34$

5.2.3 Option $3 \quad 34$

5.3 Print Accum Alarms Options ' * 38

$\begin{array}{ll}5.4 \text { Metro } & 38\end{array}$

5. 5 Tape Dump $\quad 41$.

6, 0 Program Execution and Operation: DIAG1/DIAG3̣ Program 43

6. 1 Time Code Translator Test $\quad$. 43

6.2 Bilevel Test . . . . . $\quad 43$

6. 3 Camera Test $\quad 46$

6.4 Calibrate Test . . . . $\quad 46$

6.5 Memory Controlled Processor Menu 46

6.5.1 Output Command and Read Status 49

6.5.2 Memory Test $\quad 49$

6.5.3 Memory Dump $\quad 49$

6.6 Mass Memory Menu $\quad 49$

6.6.1 Write/Read Memory $\quad 52$

0.6 .2 Read Status Registers 52

6.6.3 Write Registers $\quad 52$ 
6.6 .4 DMA Realtime $\quad$. $\quad 52$

6.6.5 Reset . . 55

6.6.6 Dump Memory $\quad$. $\quad 55$

6. 7 DIAG3 Option $\quad$. $\quad 55$

7. 0 Program Execution and Operation: 'DIAG2 Diagnostic Program 57

$\begin{array}{lll}7.1 & \text { Run MCP/MMF Without Tape } & 57\end{array}$

7.1.1 Data Run with External Signals ' $\quad 57$

$\begin{array}{ll}\text { 7. } 1.2 \text { Data Run with Cal Signals } & 57\end{array}$

$\begin{array}{ll}7.1 .3 \text { Cal Run with Cal Signals . } & 57\end{array}$

$\begin{array}{ll}7.1 .4 \text { Dump Upitions } \quad \text {. } & 57\end{array}$

$\begin{array}{ll}7.1 .5 \text { No Dump } & 59\end{array}$

7.1.6 Dump MCP Output 59

7.1.7 Dump Both MCP and MMF $\quad$. 59

7.2 Run MCP/MMF with Tape $\quad 1 \quad 59$

7. 2, 1 Data Run with External Signals 63

7.2.2 Data Run with Cal Signals

7.2. 3 Error Detection Format 63

7. 3 Tape Dump , , 63

0.0 Nova 2 Cheskout Pronenure $\quad 70$

9. 0 Calculations for the AIDS Format $\quad 71$

$\begin{array}{clr}\text { Figure } & & \frac{\text { Page }}{8} \\ 1 & \text { NIDS Hardware } & 10 \\ 2 & \text { AIDS Block Diagram } & 13 \\ 3 & \text { AIDS Data Format } & 19 \\ 4 & \text { AIARM/IALARM Software Flowchart } & 20 \\ 5 & \text { nIAC1/DIMG3 Software Flnwchart } & 21 \\ 6 & \text { DIAG2 Software Flowchart } & \end{array}$




\section{DESCRIPTION, OPERATION, AND DIAGNOSTIC ROUTINES FOR THE ADAPTIVE INTRUSION DATA SYSTEM}

\section{0 Introduction}

The development and testing of effective perimeter intrusion alarms and sensors requires a data system which can constantly monitor a number of intrusion sensors and evaluate their susceptibility to false alarms. Improved intrusion sensors would lead to the development of better alarm systems which could be expected to thwart intrusion by unauthorized groups attempting to secure entrance to facilities working with or storing nuclear materials. Figure 1 shows one of the two Adaptive Intrusion Data Systems (AIDS) built to assess intrusion sensor performance. The other AIDS is installed in a field trailer.

One special requirement of the data system was to retrieve sensor information for a five second period prior to the alarm occurrence. Normally, this might be accomplished by continuous recording and storage techniques. Digitizing the data from a large number of sensors would lead to an amount of data estimated to be $6.9 \times 10^{10}$ bits/day, or roughly 7007 -track, 2400 feet long digital tapes. This amount of data is obviously unmanageable and would probably overwhelm any data reduction facility. To meet the five second data requirement, a technique of adaptive data compression and a modest digital mass memory storage were combined and incorporated into the data collection system.

Contemporary intrusion sensors are inherently susceptible to various types of environmental conditions. Therefore, to assist in the evaluation of weather-induced alarms, a meteorological data gathering system was incorporated into AIDS. This weather system monitors and records the wind velocity, wind direction, temperature, humidity. potential gradient, and rainfall ratc. A display of the weather information is available in the instrumentation rack where an operator can observe the conditions. The weather information is also incorporated into the digital data output so that a complete history of the environmental conditions is available to the user.

In addition, the system will select television cameras observing the sensors being monitored and videotape the information at the time of any sensor alarm. Time code information is incorporated into the video stream to permit correlation of the video data to the digital data recorded.

A very important aspect of the AIDS program is the ability of the system to retrieve, reduce, correlate, and display large amounts of data in a meaningful and rapid fashion. Consequently, considerable emphasis was placed in designing AIDS in a form consistent with the existing 


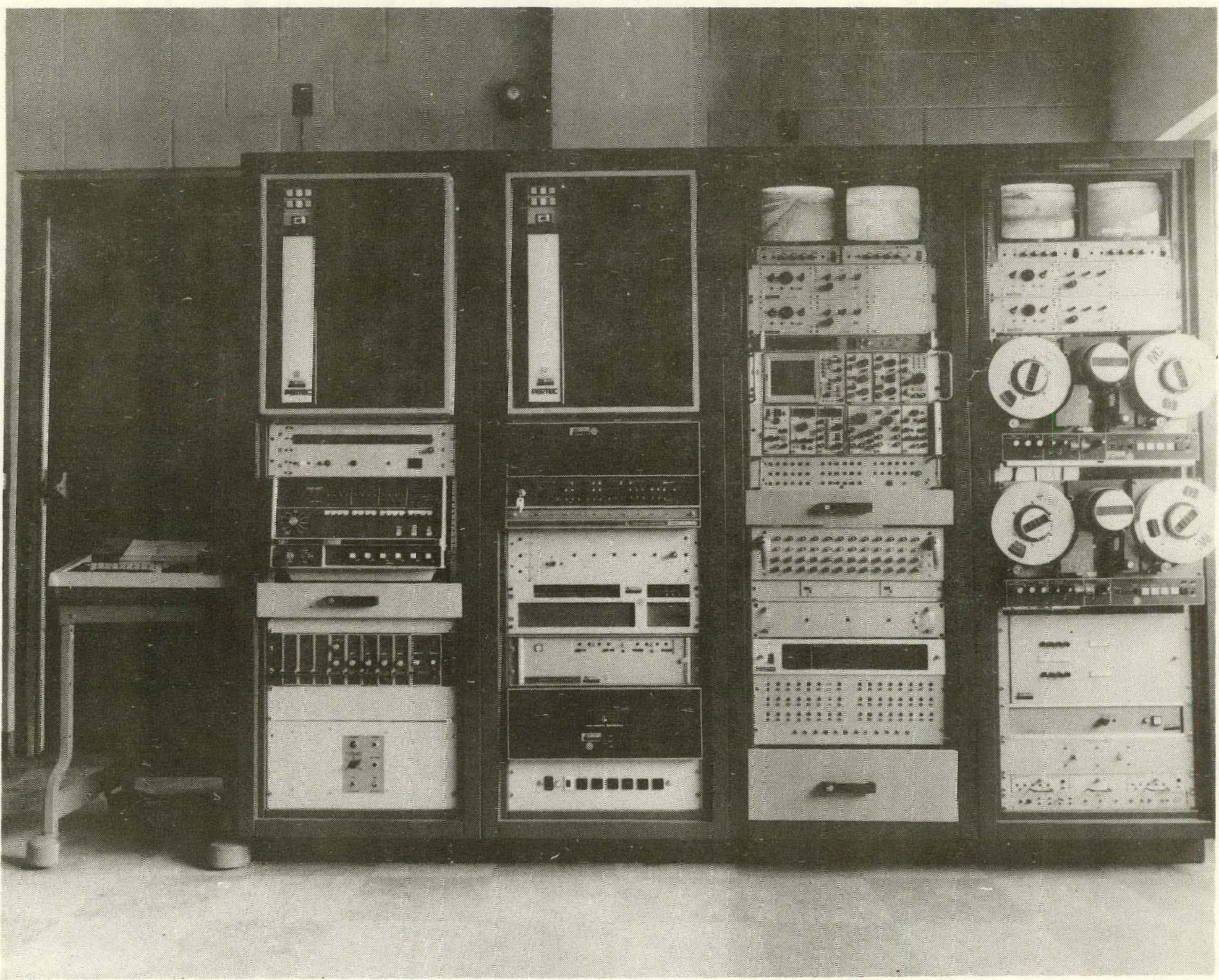

Figure 1. AIDS Hardware 
capabilities of data reduction facilities. Long data reduction times often are encountered with data that are collected in analog format. The analog data must be digitized and time correlated before computer processing. This can require extensive amounts of time from a data reduction facility. AIDS not only collects the data in the field that is desired by the user but formats the data for direct computer analysis.

An important aspect of AIDS is the ability to change the data format easily and quickly in the field, thereby permitting different arrays of sensors to be tested with a minimum of hardware changes. Data channels to be collected and data sample rates are all controlled by keyboard entries. 


\section{0 System Description}

The Adaptive Intrusion Data System was designed to be a flexible data collection system (see Figure 2). AIDS can collect data from as many as 48 analog channels. It can digitize the data into either 6 or 12 bit words and compare the data to predetermined limits and then pass the data into a 2.36 megabit mass memory, The mass memory, therefore, contains a history of the data which can be recalled whenever an alarm occurs. If no alarm occurs, then the data in the mass memory ultimately will be considered of no importance and be dropped. Upon alarm, however, the data in the mass memory will be transferred by the System Controller (a Nova 2 computer) to one of two digital tape recorders for permanent storage. When one tape is filled with data, the system will switch to the second tape. At the same time, the System Controller will print an indication on the teletype which will tell the operator that one tape is full and that it may be removed and a new tape loaded in its place.

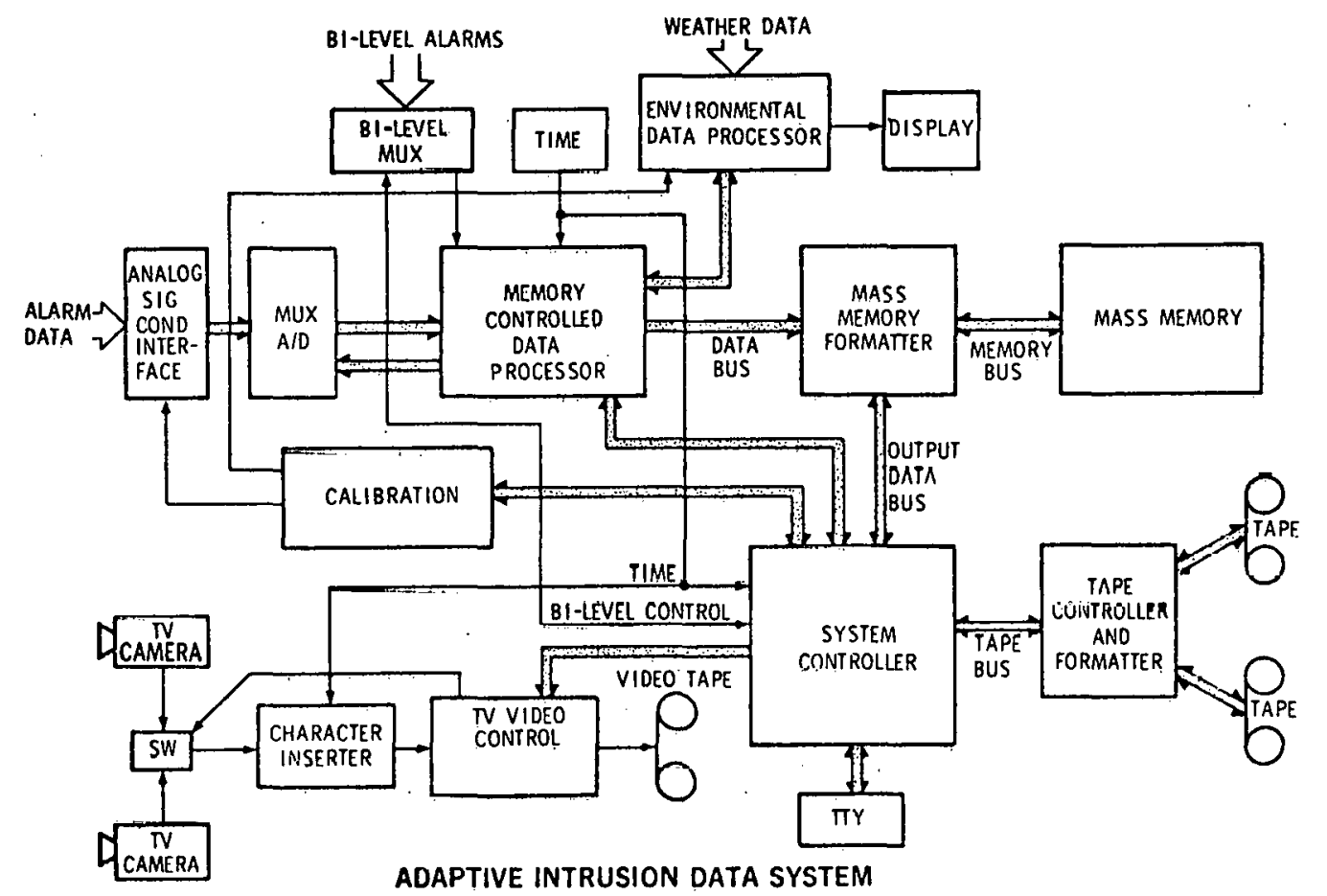

Figure 2. AIDS Block Diagram

The Fnvironmental Data Processor (an IMP-16 microprocessor) handles the weather data. Under control of a read-only-memory program, the processor constantly formats and updates the information on the weather conditions. It performs the appropriate algorithms to convert the weather data voltages supplied to it into engineering units for display. The converted weather data are then stored in its memory where they are accessible for formatting by the Memory Controlled Processor. To obtain the weather data, the Memory Controlled Processor sends an interrupt signal to the Environmental Data Processor to instruct it to route information from its memory 
onto the data bus and strobe it into the appropriate registers in the Memory Controlled Processor. Thus, the Memory Controlled Processor has access to the environmental data whenever it deșires that information.

The Memory Controlled Processor is the focal point for the collection of all of the digital data. In addition to the data from the Environmental Data Processor, it also receives time, bilevel multiplex signals, and digitized analog data from the analog-to-digital converter and multiplexer.

The Memory Controlled Processor is under indirect control of the System Controller. Whenever the user desires a particular format of data, he may enter that format via the teletype connected to the System Controller. The System Controller analyses the input instructions and - transmits the binary codes to load the memory of the Memory Controlled Processor. The memory now contains the instructions necessary to select the data inputs in the desired sequence. After the system has been formatted, the System Controller can command the Memory Controlled Processor to go into the run mode. While in this mode, it collects data from all sources tied to it and feeds that information to the Mass Memory Formatter. The Formatter in turn dumps the data into the Mass Memory. Upon command of the System Controller, the Mass Memory Formatter will take the data from the Mass Memory and transfer it to the Controller for recording on digital tape.

The Bilevel Multiplexer serves as the system trigger. Should an alarm be detected in any of the 48 channels of the Bilevel Multiplexer, the System Controller detects the presence of the alarm, determines which sensor caused the alarm, sets the system into a data collection mode, and switches to the TV camera covering the sensor in question. The video signal from the TV camera is passed through a character inserter whlch inserts into the video signal the proper time and other information in character form before it is recorded onto video tape. The Video Controller also turns the video tape recorder on for a pre-selectable length of time. The System Controller also types a record of the alarm along with the time of occurrence. The data, which are being nollested by the Meniury Controlled Processor on a continuous basis, are then retrieved for the time period of approximately five seconds before and after the alarm. This time period is software controllable. The collection and transfer of data will continue until the data have been transferred onto tape. The system will also continually monitor the bilevel inputs, and if an alarm occurs in another area or the original alarm recurs, the system will initiate a follow-on collection of the data, so that none of the information concerning an alarm situation is missed.

Analng alarm data from the sensors are processed by the Signal Conditioner on a continuous basis. The Signal Conditioner consists of 48 instrumentation low-pass filtering amplifiers. These low-pass amplifiers, which can have their cut-off frequencies altered by changing plug-in modules, act as pre-sampling filters to remove high frequency noise and also serve to reject common mode noise that is sometimes picked up on the signal lines. Upon command from the Memory Controller Proceseor, an appiuprlate multiplexer gate will be opened to take the output of the Signal 
Conditioning Amplifier. The output from this channel is fed to a sample-and-hold circuit and ultimately to an analog-to-digital converter. Any of the 48 channels can be selected in any desired sequence by the Memory Controlled Processor.

To provide a "state of health" analysis of the system and to permil calibration factors to be developed by the data reduction computer, the System Controller will at selectable time intervals perform a calibration on the analog channels and on the environmental channels. This calibration is routinely performed on every digital tape that is recorded. Calibration can also be performed periodically throughout the day, if desired.

\subsection{Data Format}

The Memory Controlled Processor is designed to handle 6-bit data words and channel codes and to transfer them to the Mass Memory Interface. 'l'he b-bit liata worda ngain appear in the formatting at the digital tape input. The format utilized (see Figure 3) consists of parallel durups of the 6-bit words with appropriate "sync" code words. The system is configured with "super frames", "master frames" and "data frames". The master frame contains the sync words. In addition, it onntains special information such as time, word rate, calibration values, and weather data. The master frame also contains the programmable part of the format, which cnnsists of the bilevel and analog channels to be monitored.

Following the master frame are the data frames. A data frame is essentially the programmable format of the master frame. If data channels are active, all data channel identification codes and their respective dala wul ds will bo prosont in the data frame. However, if the activity is such that the data are outside the thresholds programnet did no alarms are prasent. all the data frames may be dropped out of the data collection. Thus, large amounts of digital tape storage and buffer storage can be saved. The data frame end chanut codc, with its rnunt., tags any data frame present. The master frame and any number of data frames up to 4096 form what is known as a "super frame". The data system can be programmed for data rates up to 250 kilowords per second. 


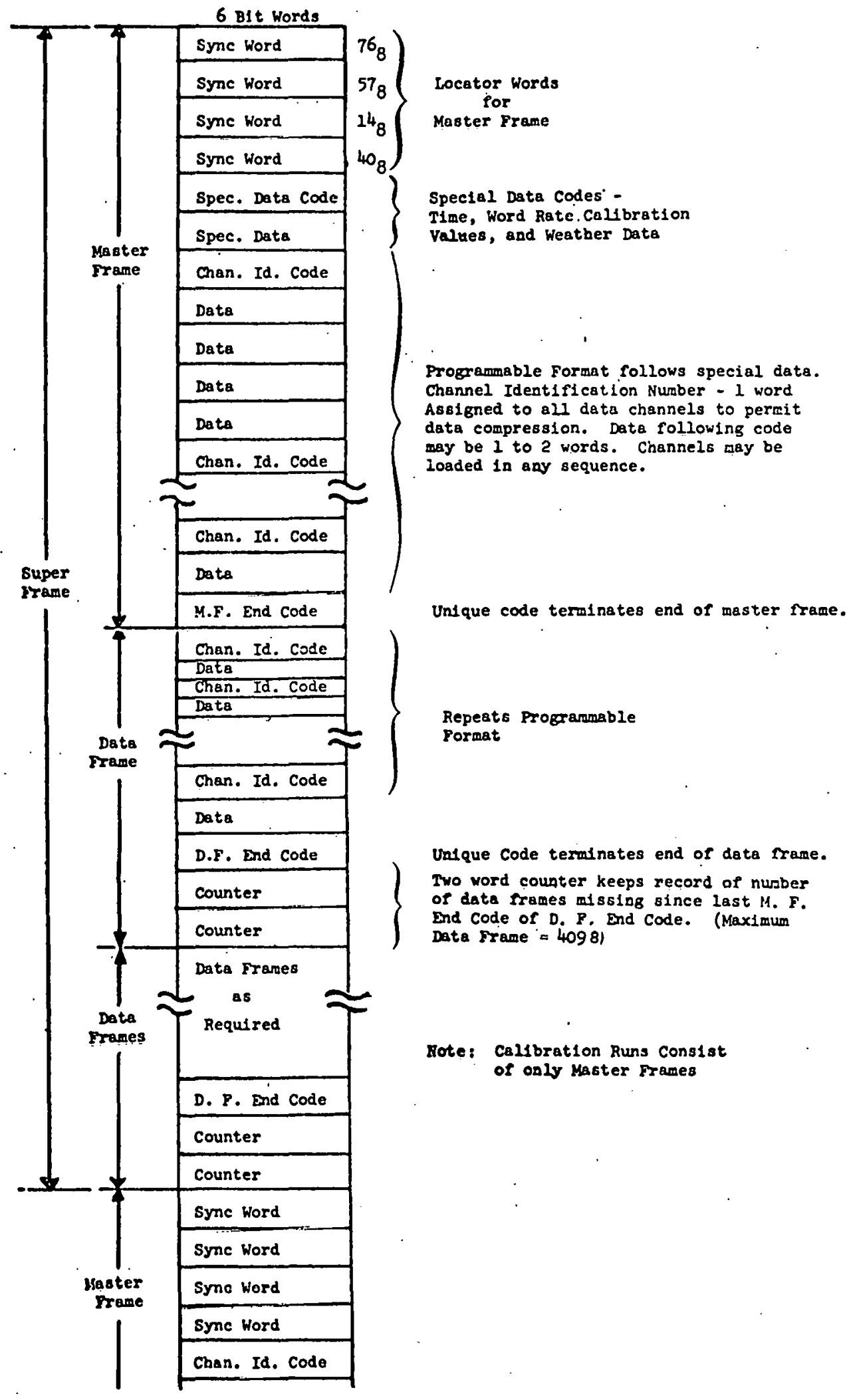

Figure 3. AIDS Format 


\section{0 Turn-on Procedures}

These turn-on procedures assume that all AIDS subsystem components have been turned off and the total system must be activated. The procedures also may be used to turn on any subsystem that must be activated after not being in use.

\subsection{Time Code Generator}

In any start-up procedure, the Time Code Generator should be turned on first. If the AIDS system has lost power momentarily, the Time Code Generator will continue to operate on internal battery power for approximately one hour. The Time Code Generator will not light its display when operating off its internal battery. If the power switch is off, then the Time Code Generator has been inoperative and must be reset to the correct time. In turning the Time Code Generator on, flyst lusu llie powor switrh to the "Qn" position. Next, deps eso tho atop hitton to stop any counters. To adjust the time, go to the preset slow code switch and dial the number to set in a digit of the time code. For example, to set the number 2 in the first digit of the days display, dial the preset selector switch to 2 and push the pushbutton under the hundreds of days. Continue this procedurc, setting the hundreds, the tens, and units for days; then set the hours, the minutes, and the seconds with the code switch. The best procedure for setting the time is to zero the seconds and wait until the next minute is due to occur. Using either the WWV or some other time cource as a reference, wait until the arrival of the time preset into the time code generator. At the proper moment, push the start button, and the time code generator will sync up with the time. The time code generator must be counting in,order to supply the necessary time information to the video system, the computer, and ulles parto of the Arns system.

\subsection{Video Subsystem}

First, turn on power to all curnelas by oporating the power swilch on the camera control units. Turn on the Lenco sync generator, the pulse distribution amplifiers, each of the monitors at the top of the racks, the remote video switcher, the Laird Telemedia Character Generator, and the videu lape recorders (VTR). With the VTR frunt panel power switch "On", the tape machines can be operated for manual playbáck ur lesording. The VTR motor control must be on for the computer to be able to control the VTR's. The remote switcher requires resetting by the Nova computer to initialize the video switches inside the camera switcher. If the screen splitter is . being utilized on the system to incurporate a fifth camera, it must also be turned on.

Monitors 1 and 2 continuously display the outputs of cameras 1 and 2 in the system. Cameras 3 and 4 monitor field "one". The Nova software routines recognize fields "zero" and "one" for switching and recording selections. Front panel switches on the remote video switcher are used to cause monitors 3 and 4 to display signals from four different sources. The field "zero" switch causes the monitors to display the outputs from cameras 1 and 2, while the field "one" switch changes the monitor inputs to the outputs from cameras 3 and 4 . The VTR switch causes the monitors to display the outputs from the two VTR's. If the VTR's are powered up in 
either the recording mode or the idle mode, the outputs will be the signals applied to the inputs; if the VTR's are in the playback mode and running, the outputs will be the previously recorded signal. The character inserter switch causes monitors 3 and 4 to display the output signal of the character inserter.

With either the VTR switches, field switches, or the character inserter field switches depressed, a display of the time will be visible on the screen. This time should correspond to the time display on the time code generator. Following the tenths of seconds count running on the screen is a number which is related to the field of view being selected by the computer at that time. It will be either field "zero" or field "one". The next three numerals display the count on the number of times the video machines have been activated by the computer system since the last manual reset. This is not the number of alarms but rather the number of times the machine has been turned on. Operation of the counter for this display can be checked by opening the remote camera switcher door and pushing a pushbutton on the lower edge of the card which is mountcd on the left hand side. Pushing the button will advance the counter an increment at a time to show that the circuit is operating. The display may be reset by a pushbutton located at the top edge of the card. This count is generally reset at the beginning of any data collection perind. The display of time directly correlates to the time code generator with the exception that the tenths of seconds is displayed on the video screen and not upon the time code generator. The position of the time and event counters can be changed by a knob on the front of the Laird Telemedia Character Generator. The characters may be activated and deactivated by pushing a recessed switch located next to the vertical position knob on the character generator. Black or white characters may be selected by pushing the $\mathrm{B} / \mathrm{W}$ switch located behind a hole in the front panel. The character generator also has a slave function which will operate to display the characters on the second video channel. The slave function does not have the same degree of character intensity control as the master.

When monitors are being selected through the pushbuttons labeled VTR Field, the video level on the VTR machine itself will control the intensity of the video display on the monitor. This should be adjusted so that the video level output from the recorder is in the green position on the meter. For individual instructinns on the opcration of the IV L ' 700 or 800 recorder, consult the manufacturer's instruction manuals.

The video monitors may be adjusted for brightness, contrast, and horizontal or vertical hold, when necessary. Screwdriver adjustments are available for adjusting the height, vertical linearity, and focus of the individual monitors. If a good picture cannot be obtained by adjustment of the monitor controls, adjust the camera controls after checking to see that the camera control switch auto/manual is in the anto position. If the switch is in the manual position, senoitivity focus and blanking will have to be adjusted manually to obtain a good picture. The auto position is the desirable operating position for most scenes. 
A good procedure to follow when turning on the remote video switcher and adjusting the monitors is to first select field "one" cameras. Adjust the monitor for best picture from these cameras. Next, select character insertion fields. The monitor now will display the output of the video switcher that is fed to the input of the VTR. If this happens to be field 0 , then a "0" will be displayed on the monitor; if it happens to be field 1, then a "1". will be in the camera select digit. At this point, adjust the vertical height position slightly until the jittering stops. Next, push in the VTR field button and adjust the video level out of the VTR until a satisfactory picture is obtained.

If after switching to the output of the VTR machine there appears to be a shift horizontally or a tearing vertically due to the horizontal misalignment, the screen splitter phase control should be adjusted with an insulated screwdriver; this control is accessible through an access hole in the bottom of the $V ' l R$. At thio time, the tape recorder's should be operated manually in the record mode to check their recording mode. After recording, playback can be accompliched ky rewinding the tape and playing back with the remote camera switcher set in the VTR field position.

\subsection{Alarm Monitoring Chassis}

The alarm monitoring chassis is activated by pushing the power switch. If alarm signals are not present, pushing the reset button wlll extinguish all the display lights. If the direct/latch mode switch is in the direct position, the appropriate displays will light only during the time the alarm signal is present. In the latch mode, the alarm will set a latch which will keep the light on until the reset button is pushed.

\subsection{Analog Signal Conditioner/Inter pace}

The analog signal conditioner is operded by turning the power switch on. When the red LED's over llie liandlog are lighted. 1t indicatco that the sigud cunditioner is in the "cal" position; they should not be on after power is turned un sincc the control relay drops out when puwer io off. If the system should hang in the calibrate position, "cal" may be resct by turning the power off and then hack on, With the signal conditioner on, any of the analog channels may be monitored from BNC connectors un the front panel. In the signal condutiunte, lhe output has a 5 volt offset and a gain of one, so a voltage of "0" volts provides a " 5 " volt output. Both the gain and offsel du'e adjustable to enable the ASCI to accommodate the unipolar analog-to-digital converter operating range of $U$ to 10 . 24 vilto.

\subsection{Environmental Data Display}

The Environmental Data equipment is located in the left hand rack beneath the Pertec tape marhine. The start up procedures for the environmental data display are as follows. Turn on the power to the signal conditioning amplifiers in the lower parl of the ruck. The precipitation signal conditioner should be reset by pushing the reset button. A light will flash while the button is depressed. The "advance" switch on the precipitation signal conditioner can be used to check the 
operation of the precipitation accumulation channel (channel 6 on the thumbwheel of the auxiliary display word selector) or to preset a value into the accumulator at power on or after a power failure. The display will count to a maximum of 255 , and the readout on the signal conditioner will increment by one. After all checks, both switches must be returned to the "OP" position.

All selector knobs should be in the operate "OP" position on all of the signal conditioners. Next, turn.the display panel power switch on; no digits will be displayed except for the permanently lit decimal point. Next turn on the IMP-16L microprocessor; the IMP-16L should immediately go to the "run" position, and digits should now be displayed on the environmental display panel. The rainfall rate indication will not be correct until four minutes after the system has been turned on; at that time, the rainfall rate will be updated for display. The display should be in the enabled position. In the disabled position, the displays go off and the disabled LED lights. The lamp test can be accomplished by pushing the lamp test button, in which case all digits displayed will be eights. Two switches located in the lower right hand corner labeled "Auxiliary Display Word Select" will select displays for auxiliary inputs that may be attached to the processing system. These displays select alternate wind speeds and wind directions from other sectors than the main sector for the Rocky Flats installation.

The Potential Gradient Sensor Control is turned on next; allow five minutes for warm up and then push the zero button. A potential gradient of -200 (20. on readout) volts should appear on the display panel. The Potential Gradient Sensor Control also has a buzzer switch which enables a buzzer to indicate when the potential gradient exceeds that value selected by the front panel control. This circuitry has no effect upon the data collection or the display.

Occasionally, the potential gradient may latch up; this is evidenced by a display value of 999 . To correct this condition, turn off the power to the Potential Gradient Sensor Control for a few seconds and then turn it back on. Cycling of the potential gradient power switch should unlatch the circuitry. In some cases, this condition is self correcting. 


\section{0 Nova 2 Computer Operation and Software}

The Nova 2 computer is the system controller for AIDS and performs the functions of both operating a "Run" program and furnishing diagnostic programs to analyze problems associated with components in the system. The following procedures must be followed in order to place the Nova 2 into operation for either a system "Run" or to diagnose problems with the system. Turn on the Nova 2 power switch and the AIDS Mass Memory Interface. The Mass Memory Interface must be on since the Nova data bus terminations are localed in the Mass Memury Interfaoe. Turn on the Pertec tape machines and the Datum magnetic tape controller. Thread the digital tapes onto the Pertec tape machines per the instructions located inside the cover of the Pertec.

\subsection{Software Description}

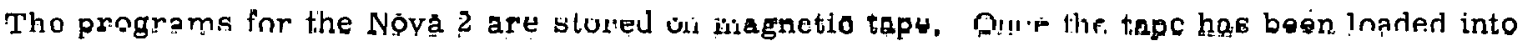
the computer, the programs will remain in residence in the computer until such time as a new program is over-written, destroying the program in residence, The system digital tape contains five programs: DIAG1, DIAG2, DIAG3, ALARM, and IALARM. If the Adaptive Intrusion Data System is to he placed into a data collection mode, either the ALARM or IALARM programs must be loaded into the computer. The programs are basically the same and contain the aame informatton except that IALARM has an abbreviated set of routines that does not contain a tape dump option that the ALARM program contains. IALARM is to be used when the computer contains only $16 \mathrm{~K}$ of memory, and ALARM can only be used when there is $32 \mathrm{~K}$ of memory in the computer. Figure 4 shows the flow diagrams for initializing ALARM or IALARM functions.

If the Nova 2 is to be used to diagnose subsystem maltunctlu!s, llien DIAC1, DLAG?, nr DIAG 3 must be loaded into the computer from magnetic tape. DIAG 1 and DIAG3 are essentially identical programs except that DIAG3 contains an additional set of tesl 1 untinco that can be usen only when the computer contains $32 \mathrm{~K}$ of memory. Figure 5 shows the flow diagram for these two routines and indicates that DIAG3 contains a metro routine not present in DIAG1. DIAG1/DIAG3 diagnostics are used to check out individual subsystem components. The DIAG2 program contains diagnostic routines that permit the AIDS to be run in special run formals for diagnoetic purposes only, Since DIAG2 is used in run-like mude conditions, many of the routınes and subruulines arc similar to those in the alarm programs. H'igure 6 slows the flow diagram for DIAGR. 


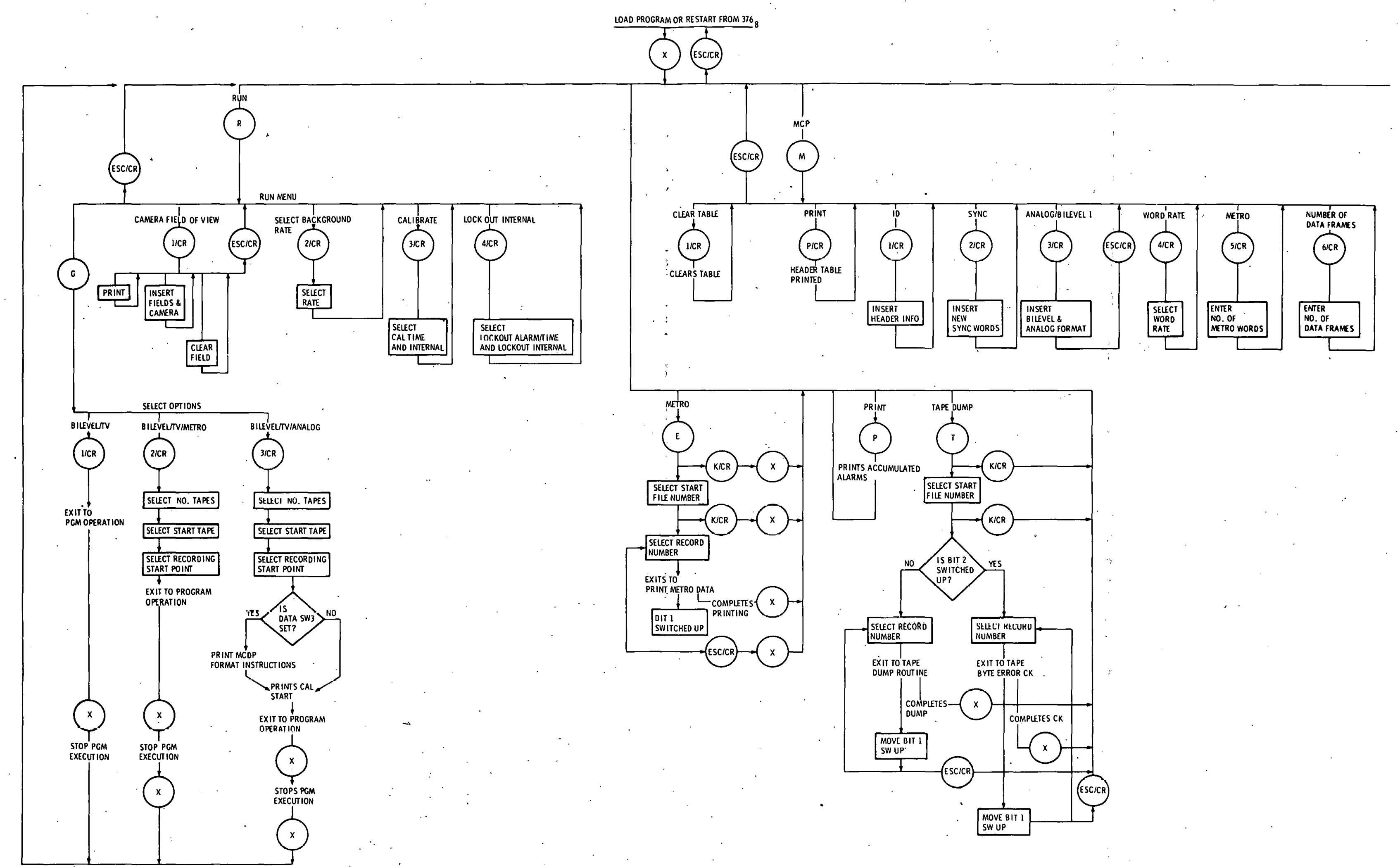

Figure 4. ALARiM/IALARM Software Flowchart 


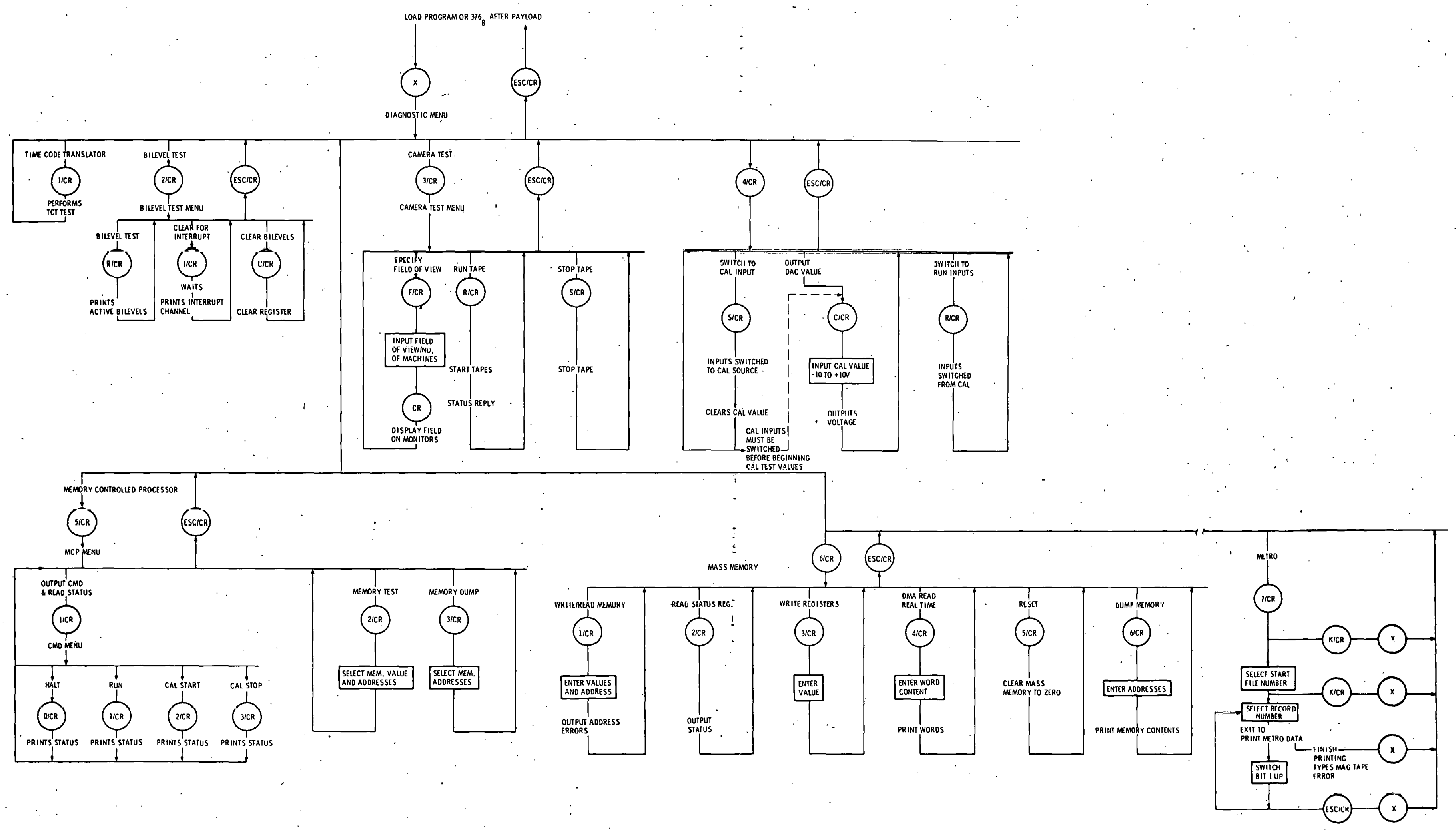

Figure 5. DIAG1/DIAG3 Software Flowchart 

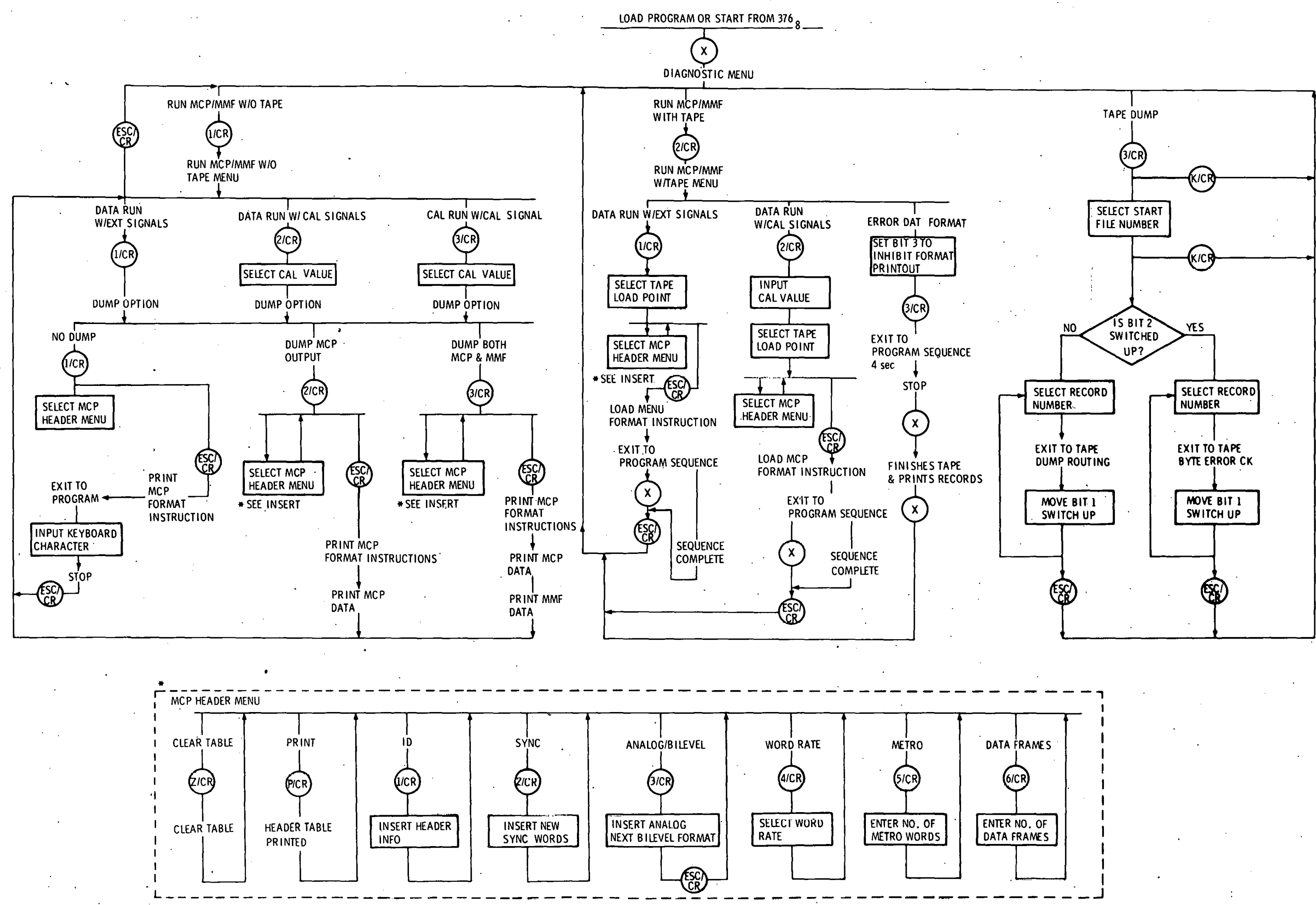

Figure 6. DIAG2 Software Flowchar 


\subsection{Program Tape Loading}

Any of the five programs may be loaded into the computer by following the procedure outlined in this section. The program tape should be loaded onto machine 0 . After threading the tape machine, push the load button and the machine will activate to correctly position the tension arms and the tape. Depress the load button a second time. The tape should advance to the "Load" position if it has not been threaded past the load point. The "Load" light will come on when the tape reaches the load position. If the tape continues to run, stop the machine and reverse the tape because it has been threaded past its load sense foil. A digital tape with a write ring installed must now be placed on machine 1 and the machine placed in the on-line condition.

Check the switches on the magnetic tape controller. The $\mathrm{A}$ switch should be in a "On position, selecting machine 0. The B switch should be in the "1" position, selecting machine 1. Machine 0 is the left hand machine in the first rack, and machine 1 is directly above the Nova 2 computer. The parity switch should be placed in the "Odd" position. The mode switch should be moved to the "Remote" position. The density switch should be thrown to the "High" position, and the packing switch should be in the "664" position. Switches $C$ and $D$ should be moved to select position 3 .

Activate the tape machine 0 to on-line. At this time, the machine should display "Load", "On-Line" and "High" density lights.

\subsection{Program Load Sequence}

The software program can be loaded into the computer by performing the following steps. The computer should be in the "Stop" position; that is, the "Run" light should be off. If it is not, the computer can be stopped by moving the switch labeled "Reset-Stop" to the "Stop" position. Next, the data switches should be activated to insert the octal 100022 . This code is entered by throwing the switches labeled 0,11 , and 14 to the up position. Next, turn the teletype on and switch it to the on-line position. Check to insure that the paper is properly loaded into the Silent 700 teletype. With the machine on, paper can be advanced.

Depress the Nova "Reset-Stop" switch to the "Stop" position and then move the switch upward momentarily to the "Reset" position. Operate the program load switch by momentarily moving it to the "Up" position. The digital tape machine 0 will move from its load point, and the load light will go out. The teletype will respond by printing "Program Title?". At this time, the operator may enter on the teletype the title of the program; for example, it could be "ALARM" or "DIAG2" or any of the other programs on the program tape. After typing the program title, the operator should type a carriage return. Carriage return on all of the flow charts is indicated by a CR. At this time, digital tape machine 0 will move forward and load the program from the tape. After loading the program, the teletype responds by printing out RTOS, REV 4.00 on one line, followed by the word READY on the next line. After the teletype has responded, the operator should type "X" on the keyboard. The response of the computer will depend upon the program that had been entered. For example, if ALARM or IALARM had been loaded, the computer will respond by typing INIT OPTIONS. The computer program is now setting at the first option level in the instruction set. 
At any time and during any operations, the program can be returned to its starting point by entering $376_{8}$ on the data switches on the front panel of the Nova computer and going to "Stop", "Reset", and "Start" with the front panel switches. This action will reinitialize any of the programs and return them to the top of the flowchart. There are times when an operator will find that the computer has started into a long routine that he wishes to terminate but there is no escape from that routine indicated on the flowcharts. In this case, the operator has no other alternative but to terminate the program and begin again from the load point. This is always accomplished by entering the program again via $376_{8}$ and the control switches on the Nova front panel. At times when the syotem is not operating properly, the Nova will not receive the correct signals from the hardware interface and will set and ignore all commands from the keyboard, thereby requiring the operator to use the front panel restart system. It should be noted that when a program is loaded from tape, a number of the selected variables are always placed at their default value and certain other variables, such as channel programming, will not exist in the newly loaded program. However. after a format has leen loaded into memory and the variables entered by following one of the routines, it will not be necessary to. reload those variables when the $376_{8}$ starting address is used.

In normal operation, a prugram loaded into the computer can be recalled by entering $376_{8}$ and starting the program from the Nova front panel. If there are no changes in the format of the program, the operator may make a few simple selections via the keyboard and have the program running again. After the program has leen loaded into the computer, it is possible to remove the program tape and replace it with a data tape to enable machine 0 to be used for the collection of metro or analog data. The program is rewound and replared by the digital lupe, and in such cases une must ensure that the write ring is preșent on the liack uf the digital tape being loaded. The computer program checks to see that the write rings are present; if thcy are $110 t$, 1t will terminate the sequence until the rings are installed on the tapeo that are intended for data collection. After the machine has been loaded with tape, the "Write" enable light will come on to emphasis the fact that the "Write Enable" ring is present. Program tapes should be protected by never installing a "Write Enable" ring.

Before beginning dal solleotion, tape cuntroller switches should be checked again to see that they are in the following positions: $\Lambda$ switch on "D", B switch on "1" and $C$ and D switches on "3". Parity is in the odd position. The mode switch is placed in "Remote". The high density is in the high position, and the packing switch is in 664 position. These are considered to be ptandsint pnaitinns for the tupe controlle1. Suftware in the program of the Nova will take care of changing the operation of the controller when necessary. For example, program tapes have a 661 packing format, while data tapes use a 660 packing format. After all tapes have been loaded and switch positions verified, the program can be started by placing the data switrhes on the Nova ill the $31 / 6_{8}$ positivis, thus going to Stop, Reset, and Start. The teletype will respond with RTOS REV 4.00 READY. Next, type "X" on the keyboard, and the initialization options will be printed out for the program selected. 


\section{0 Program Execution and Operation: ALARM Program Loading (Figure 4)}

The software for the AIDS program operation has been written to be self-guiding so that the operator is constantly prompted by the computer as to what steps should be taken next. It is possible, however, for the operator to be confused about which level of control strings he is generating. To make the functioning of the program clearer, a flowchart for the three basic programs has been generated and is shown in Figures 4, 5, and 6. As previously indicated, the ALARM and IALARM programs are identical, with the exception of one additional program option for the ALARM program. IALARM does not contain the tape dump routine and cannot be loaded into the machine unless the Nova 2 has $32 \mathrm{~K}$ of memory. DIAG1/DLAG3 programs are essentially the same, with the exception that the DLAG1 program does not contain the Metro option. The DIAG3 program can only be loaded in a computer with $32 \mathrm{~K}$ of core memory available. As shown in the flowcharts, these programs can exist in a computer one at a time only. Loading one program wipes out the previous program in the computer. The options that the operator has when running a program are described below; the pertinent flowchart is used as a guide.

After the ALARM program is loaded into the computer, type "X" on the keyboard. The computer responds with "INIT OPTIONS" and prints out each of the available options; the operator selects the option he desires. The control program is now setting at an option level which allows the operator either to choose one of six branches or to type ESC/CR and return back to the program load level (ESC is an abbreviation for Escape, and CR is an abbreviation for Carriage Return). Example 1 shows the option that the operator may now exercise at this program option level. Each of the available option choices will now be discussed. Note: After loading the program from a magnetic tapc or restarting it from 376, the option I in the INIT Option Menu must be selected. One or both digital tape machines must be initialized before the computer can be run in the Metro or Analog mode which requires one or both tape machines to record data,

\section{$5.1 \mathrm{MCP} / \mathrm{HEADER}$}

Typing $M$ un the lcoyboard moves the program to another option level. The $M$ is not echoed back by the computer, so it does not print. The computer instead prints MCP/HEADER. MCP is an abbreviation used in the computer programming relating to the Memory Controlled Data Processor. HEADER refers to the header on the magnetic tape that will be printed whenever the program is placed into the run mode. In Figure 4 , it shows that if a $P$ followed by a carriage return (CR) is typed, the header MCP table will be typed so that the operator can see what is stored. This is not necessary if the program has been loadcd from the tape since the values in the table will indicale only the default values. Typing $\mathrm{Z} / \mathrm{CR}$ clears the table of any variables loaded in the analog-bilevel section. (Each time the program is loaded from tape, it will bc nesessa.ry to go through the MCP/HEADER program to reload the variables required for program operation.) 


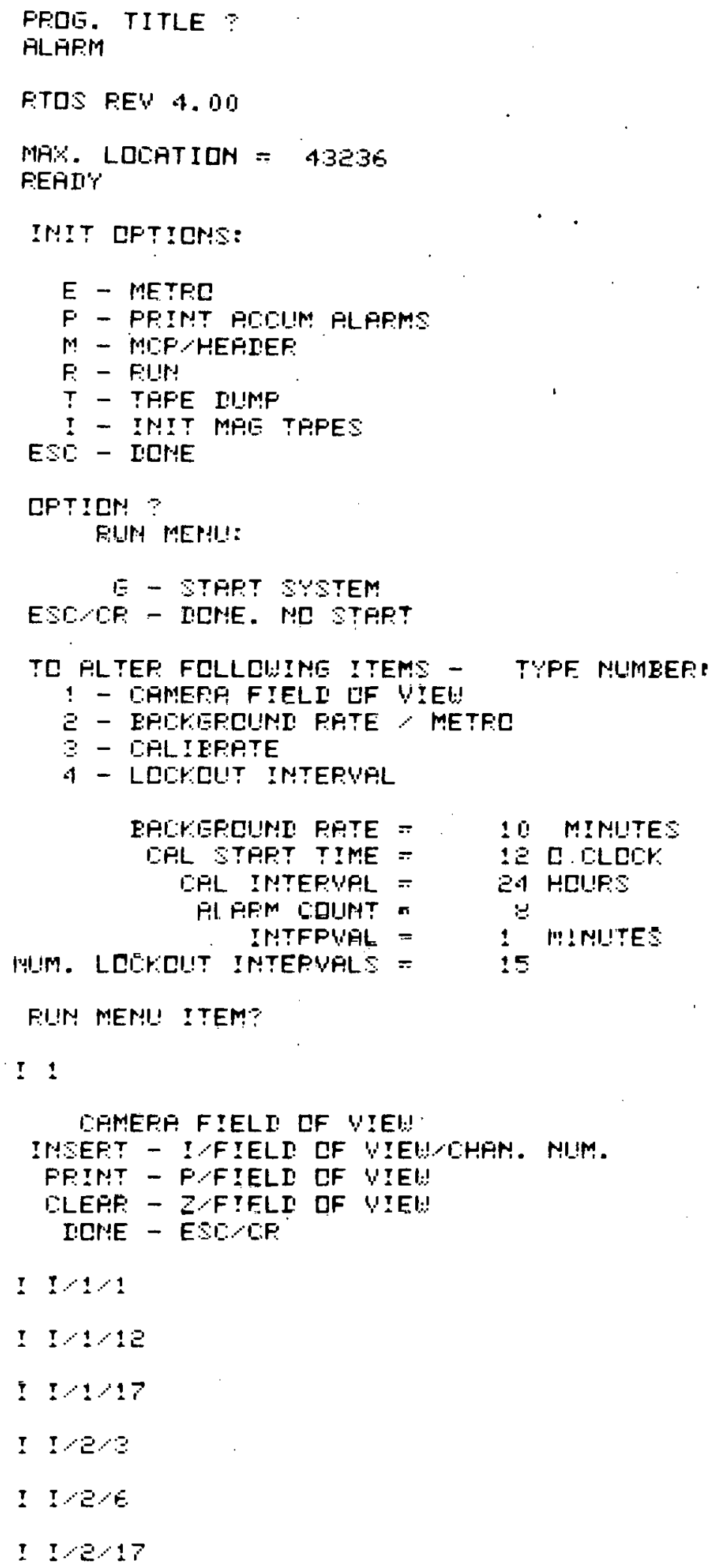

Example E-1 


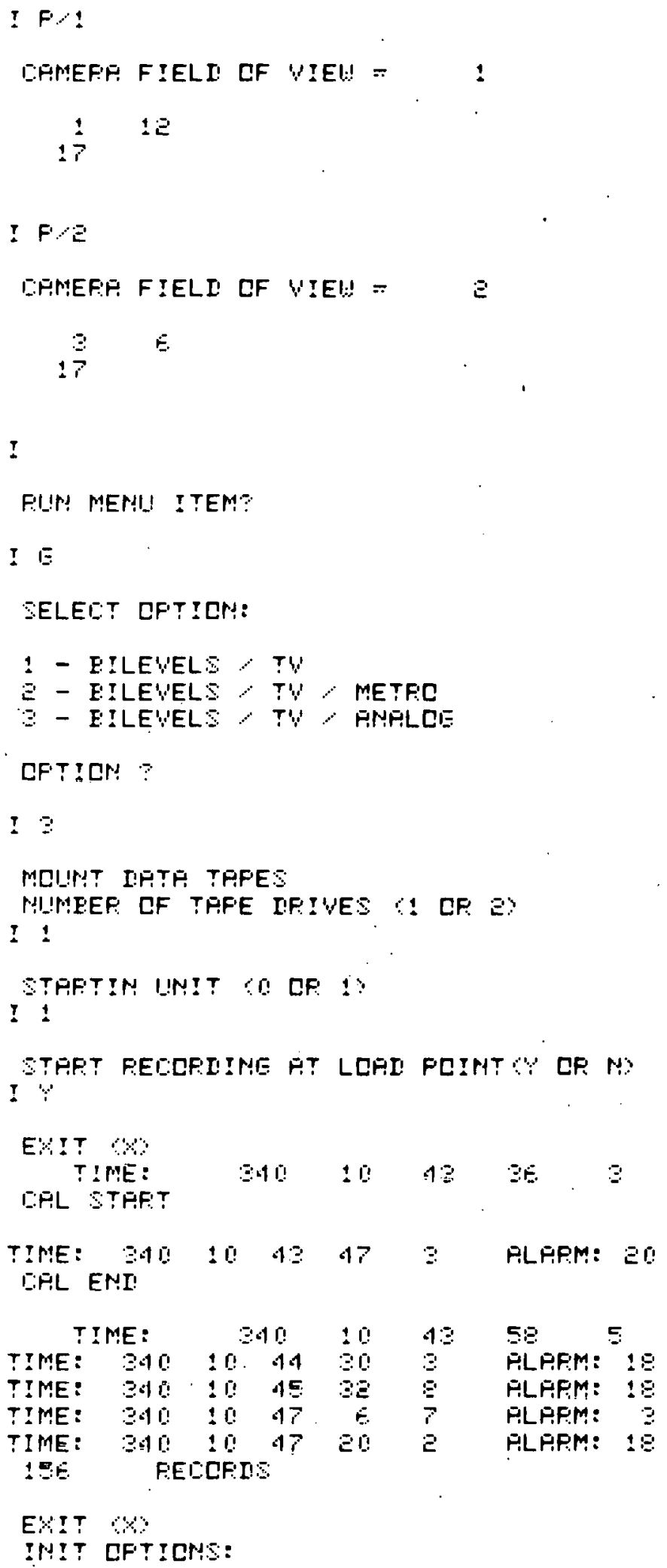

Example E-1 (Continued) 
Typing 1/CR moves the program to the ID section. The ID section allows the user to enter information concerning the test that is to be conducted. This information is transferred onto the headers of the digital tape and remains a permanent reference on the digital tape. The operator may enter up to 28 characters in this section. Typing $2 / \mathrm{CR}$ brings up the sync section, which is not shown in the example. Gencrally, the sync is not changed and is allowed to run at its default word value. The sync as choosen has a low probability of occurring in any sequence of data words or channel codes.

Typing 3/CR will call up the analog-bilevel section. It is in this section that the channels are programmed in the sequence with the threshold values desired. Channels may be entered into the analog-bilevel section in any random sequence desired. The only requirement is that no channel be repeated in the sequence. This is not a constraint on the processing by the Memory Controlled Data Processor, but it is a restraint impnsed by the soflwalt? program used in the data reduction facility. If the tahle ha bccn zerued ur cleared due to a previous load of the program from tape, the operator may simply enter channels as shown in Exauple 1 . 'l'ho "B" indicates a bilevel, "A" means add to the table, and "1" means the first group of bilevel words, which are channels 1 through 24. Next is shown the instruction for entering an analog channel. The first "A" means analog. The second "A" means add, the " 4 " means channcl 4 , and the "6" is the number of data bits for the channel. The next two numbers indicate the upper and lower threshold voltage for the channel. Example 1 shows 10.24 for an upper threshold and 0 volts for the lower. These voltages indicate that no data compression will take place. If a voltage less than 10.24 had been chosen, all data above that chosen voltage would be deleted during the comparisons made on the data channels and would not appear in the output data stream. If the lower threshnld wero higher. than 0 , all dald sampies below the lower threshold would he eliminated. Deletiur of data voltages only occurs in data frames and not in the master frame, so it is always possible to find data samples to verify what the actual voltages were on a channel that is quicocent. The master frame sample gives some assurance that thr analog-tu-digital cunverter was operating correctly.

The sample shown has been a simple addition to the table. If it had been added to a table already containing other format instructions, it would appear at the cnd of that table. If it is added to a blank table, it woyld, of course, appinr at the bcginnilig. The program has the capability for performing three other editing functions on the analog/bilevel section. The table can have replacements added to it, deletions made from it, and insertions made into it. For example, if the operator typed "A/R/4/2/6/10/2", he would have been replacing the fourth entry in the table with the second channel of analng data $s i \mathrm{k}$ bits, an upper threshold of 10 and a lower threshold of 2. By using replacement, any word or values within the word can be replaced in a table without having to retype the whole table. To execute a deletion from a table, the operator types "A/D/5". This instruction simply deletes the analog channel from the fifth entry in the table. The value following the $D$ is the entry number in the table to be deleted. The final editing capability permits insertion of instructions. For example, if the operator typed "A/I/4/3/12/7/3", he would be inserting a value after the fourth entry in the table. This entry would be an analog channel with a 12 bit data word and upper and lower threshold voltages of 7 and 3 volts, respectively. 
After the operator has completed the construction of his format, in the analog-bilevel section, he may return to the previous option level as shown in Figure 4 by typing ESC/CR.

The next programming an operator can do is related to selecting the word rate for the Memory Controlled Data Processor. Type 4/CR and the program will type the word rate selections, which vary from 250 kilowords to 7.8125 kilowords per second. The choice of the word rate is determined by the operator based upon the sample rate that is required for the highest channels in the format. Once a code is typed for the selected word rate, the program will return to the option level.

Typing 5/CR allows the operator to select the number of metro words that will be in his format. It does not change the number of metro words that will be output by either of the Memory Controlled Data Processors at either Rocky Flats or SADL. The actual selection of the number of metro words is done by a firmware program inside the Memory Controlled Data Processor and the Environmental Data Processor. The selection here must be made so that the data reduction program will know how many metro words are present in the data. The default value for the number of metro words is 11 and is correct for tapes done at the Rocky Flats facility. Programming for the SADL facility should be set to 7. Upon typing the number of metro words, followed by CR, the program will go back to the option level.

The number of data frames to be programmed is selected by typing 6/CR. The computer program will ask for the number of data frames, and the operator may select a number between 1 and 4095. After typing $\mathrm{CR}$, the program returns to the option level.

Although it is not necessary, it is good policy after loading the program to check that all variables have been entered correctly. This can be done by typing P/CR. As shown in Example 2 , the ID section header information and all the variables entered will be printed for inspection. Note that the sync section prints a number indicating the number of sync words entered in the program followed by the pattern of those words indicated by the decimal equivalent of the 6 bit binary word used for a sync value.

The table at the bottom indicates the sequence of the channels that will occur in the data frame. The channel number, the number of bits requested for each analog channel, and the upper and lower threshold values rounded to the nearest binary value that the computer can output are displayed.

After completing the printout, the jiogram returns to the option level. The operator has completed all the possible choices required in the MCP/HEADER section. To return to the INIT OPTIONS level, type ESC/CR.

The operator can choose any of the other options at this program level. The option of primary concern is run, which will now be discussed in detail. 


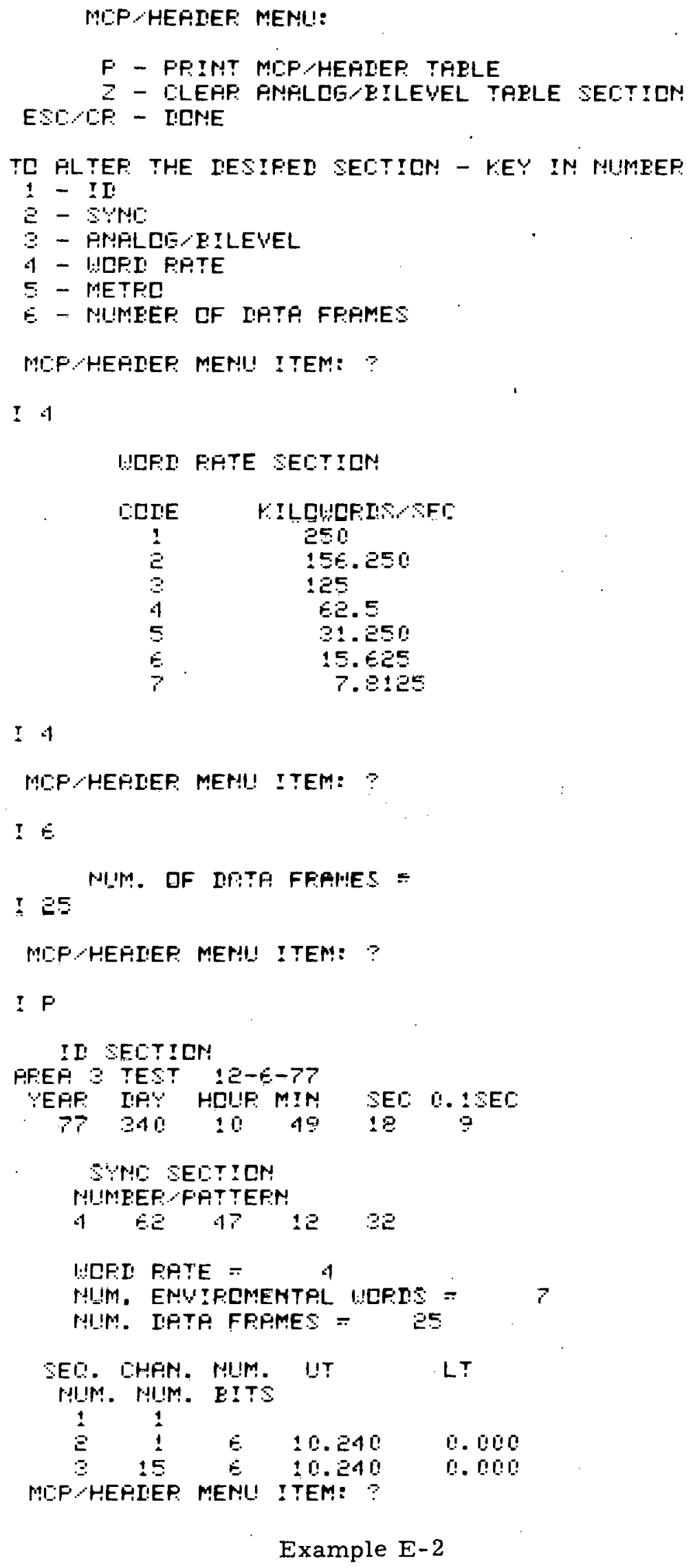

I 1

MLF CHEFIER MEH!I! ITEM: $?$

$I$

Example E-2 


\subsection{R-Run}

Figure 4 shows that the run menu may be called up from the INIT OPTIONS level by typing $R$ on the teletype. Example 3 shows the printout offered under the run menu. The operator can go to "G" to start the system or use an ESC/CR to return to the INIT OPTIONS level. At the run menu level, the following can also be programmed: camera field of view, background rate for metro, calibrate interval, and lockout interval. Example 3 shows the values that the system will default to for calibrate, background, and lockout if new values are not inserted at this program level. The camera field of view can be programmed by typing 1/CR. Under this programming level, the cameras covering a particular field of view are associated with alarms in this field of view. By proper association, an alarm will cause the computer to switch and record on video tape the output of the cameras covering the field of view where the sensor that generated the alarm is located. Under the field of view, the operator can insert, print, or clear all the associated cameras and channel numbers. Example 3 shows how a sample programming would take place. After programming and checking to see that the programming is proper by having it printed out, the operator can return to the run menu level by typing ESC/CR.

To program background rate, the operator types $2 / \mathrm{CR}$ and enters the rate; the program will return to the run menu option level. To insert calibrate, times, and interval, the operator types $3 / C R$ and enters the values; the program will return to the option level.

To select the lockout interval, the operator types $4 / \mathrm{CR}$ and enters the values; the program will return to the run menu level. A lockout interval programs three things: the alarm count, the interval number, and the lockout interval. For example, the system can be programmed to count any number of alarms in time intervals from 1 to 59 minutes, and if this number occurs for any of the bilevel channels, the program will lockout that channel and will not respond to that channel for the length of time that is programmed for the lockout interval,

Any of the selected values for background rate, calibrate, or lockout intervals can be reprogrammed by simply entcring new values after selecting the menu item.

After the operator is satisfied that all run menu items are properly programmed, he may continue to the run options level. Type $G$ and the computer will ask for the option. Three options are available. The Bilevel/TV option will print the time of alarms and record the camera signals on video tape. The Bilevels/TV/Metro option will also record the bilevels and will record the camera signals on video tape. In addition, the metro data will be collected and transferred to digital tape, The metro values will also be printed on the teletype at the intervals requested by the background rate. The third option is Bilevel/TV/Analog. It will record the bllevels on the teletype printout and at the same time record video on the video tape machine. Analog data per the program inserted under the $M$ option will be processed and recorded on digital tape. The system will also make periodic printings of the weather data interspersed throughout the alarms. 
FI!IN MENI!:

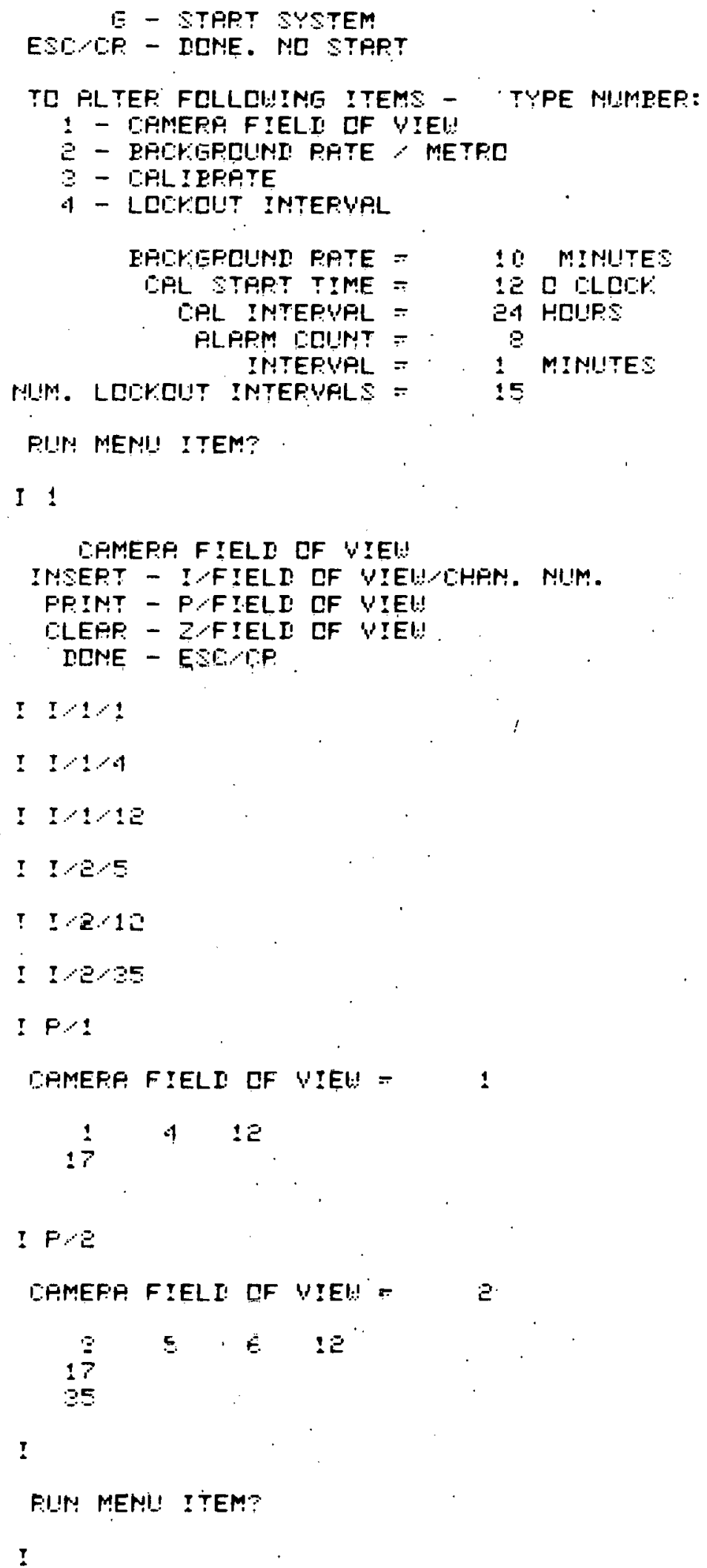

Example E-3 
$\Xi$

EPGRERIIND PRTE -

I $=0$

PUIN! MENIL! ITEM?

I $\Xi$

INFILT - STPRT TIME INTEPYAL

I 12

FIL!N MENI! ITEM!?

I 4

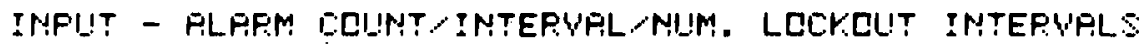
I 100020

FIUN! MENI! ITEM?

Example E-3 (Continued) 
5.2.1 Option 1 -- When the Bilevel/TV option is chosen, the computer immediately proceeds to start collecting alarm information, printing out the time of occurrence and the alarms referenced to the alarm number. Example 4 shows the result of a printout under option 1 . Typing $X$ on the keyboard will stop the program execution and return the program up to the INIT OPTIONS level. The operator must check the video tape recorder to verify that it is ready for recording.

5.2.2 Option 2 -- The Bilevel/TV/Metro option is chosen by typing 2. Since metro data will be collected on digital tape under this option, the operator must answer the following questions, and make the necessary selections and preparations for digital tape data collection. Example 5 shows a sample of such an implementation of option 2. The number of tape drives is selected along with which unit will be the starting unit. Next, the recording load point must be selected. If the computer program receives a $Y$ or yes for an answer from the operator, it will immediately begin recording after the load point at the beginning of the tape. If the operatur enters no, then the computer will sheck through the tape until it finds the double end of file mark and will begin recording at that point. This allows the operator to collect continuous strings of data onto one digital tape. If he starts a new tape, he will answer $Y$ or yes to the computer program. If he has run a number of tests before, and is keeping them in sequence, 'he will answer no so that the computer will start recording at the end of the data that he has on the tape. If the operator fails to properly terminate the program sequence of the digital tape, it will be difficult to recover the data from the tape because no double end of file mark will exist. When all steps have been taken, the computer will begin the program execution by typing the time that alarms occur, which alarms occur, and the weather data at the selected background interval. The metro data will be collected on the digital tape and may be recovered at a later time hy utiliaing the welro clump routine avallable from the INIT OPTIONS level. The program will cuitinue to operate, collecting metro dala until the operator stops the program execution with an "X" nn the kcyboard. A second "X" is required to return the program to the INIT OPTIONS level. The operator must check the video tape recorder to verify that it is ready for recording.

5.2.3 Option 3 -- The Bilevel/TV/Analog option requires setup similar to option 2 as far as the digital tape units are concerned. The operator must properly mount the data tapes and tell the computer the number of tape irives, thc start unit, and whether the tape should start at the load point or at the end of some already existing file on the tape. After the program information is loaded and the load point selected, the computer program will move the tape to the proper starting position and begin a calibrate sequence. A 21 step calibrate will be run on all the data channolo and collected in the records at the beginning of the file. Bilevel alarms and metro data will be collected and typed onto the teletype printout. As indicated in the flowchart (Figure 4), if data switch number 3 is set in the up position the format instructions going to the Memory Controlled Data Processor will be printed for inspection. If the switch is in the down position, the program will bypass lhe printing of the Memory Controlled Data Processing instructions and go directly into its calibrate routine. The operator can terminate the program by typing " $\mathrm{X}$ " on the keyboard. A second " $\mathrm{X}$ " on the keyboard returns the program to the INIT OPTIONS level for any further instructions the operator may want to initiate (see Example 6). 


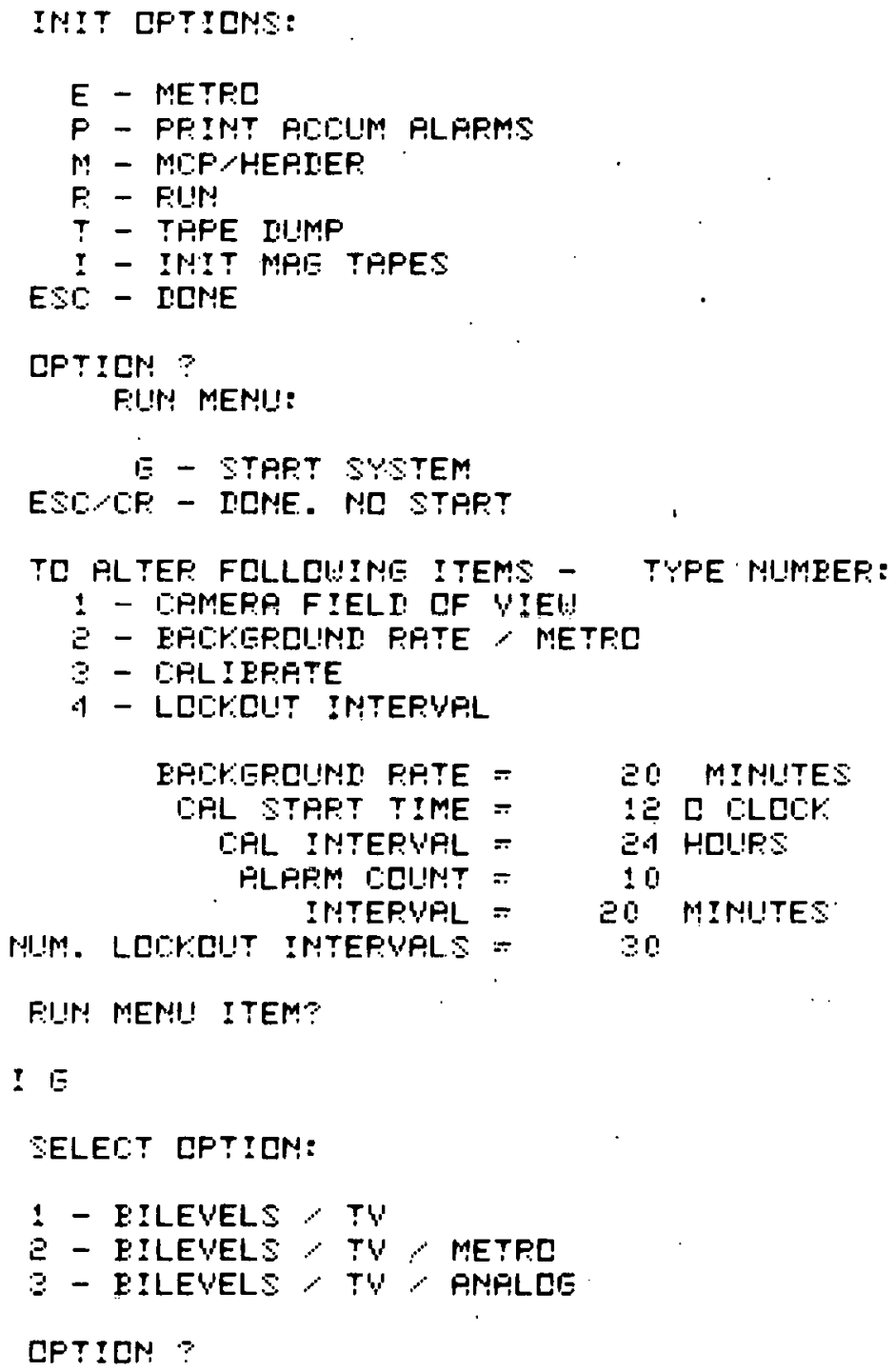

LFT!CN ? 
FIIIS HEP!I! ITEM?

I

ERIEFEFCLIPII FIPTE -

I 1

FILI! r.EF!I! ITEM?

IE

SELER:T CFTICH:

\pm - FILEWELS TU

$\Xi$ - EILE

$\Xi$ - EILEYELS T\% AR!ALCE

CFT ICH.

I

rQLITT IIFTP TFFES

PIIMEEF CF TFFE IIFIVES $\&$ CF:

I:

STFF:TH UPIT CO CF 13

I \pm

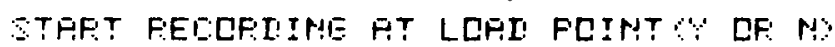

I $\because$

$$
\text { EXT }
$$

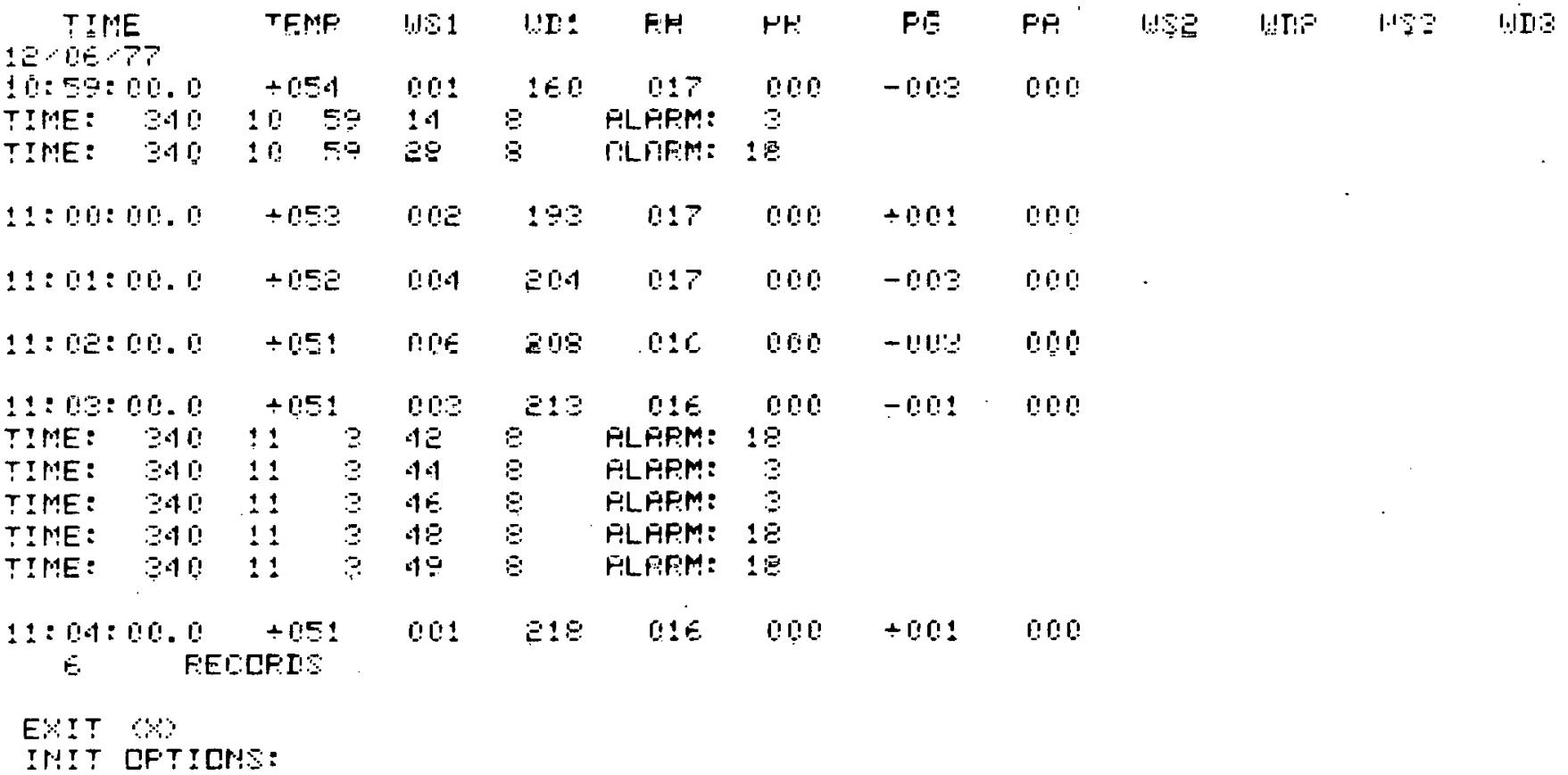

Example E-5 


\section{FII!H! M!EN!I!:}

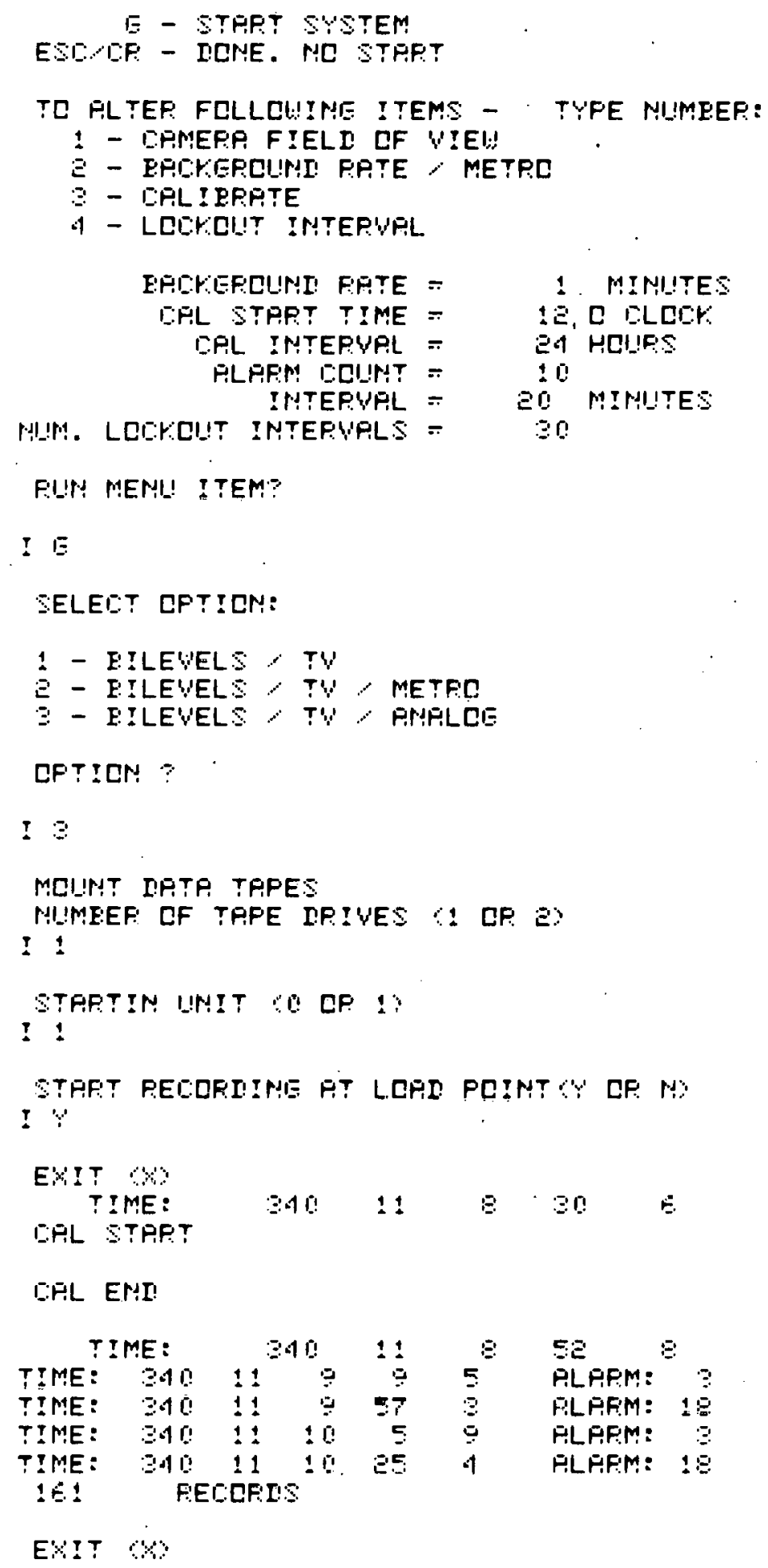

Example E-6 


\section{3 Print Accum Alarms Options}

Once a number of alarms have been collected by the system in any of the options, the operator may request to see the total number of alarms that occurred in the "Run" interval. With the computer at the INIT OPTIONS level, the operator may type "P" on the keyboard. Example 7 shows a printout and the respective accumulated alarms for each of the active channels in the format. The program always prints out all 48 channels regardless of the format. The registers containing the accumulative total number of alarms will retain the information until the operator again goes through the "G" option in the run menu. At that time, the accumulated counts will be cleared and the program reset to receive a new accumulation of alarms under the next selected run options.

\section{$\underline{5.4 \text { Metro }}$}

The metro uption provides the capability of rearing bask a digital taje will unly metro data stored on it. To execute this program, the previously recorded digital tape is loafed onto machine 1 and the machine placed on line. $E$ is typed on the teletype, and the program is prepared to select the metro data for printout. The operator must, as shown in the example in Figure 4, type in the correct file number. He can at either this or other option points in the program type ESC/CR followed by an "X" to return the program to the INIT OPTIONS level. After selecting the record number, the program will begin the typing of the metro data. If all the data within a given record are typed, the program will terminate the typing and be ready to return to the INIT OPTIONS level following the typing of an " $\mathrm{X}$ " on the keyboard. If the operator does not wish to view all the metro data, the bit 1 on the data field of the Nova 2 can be switched up and the computer will momentarily look at the position of bit 1 and upon finding it in the 1 position, will terminate the typing. As shown by the flowchart, the operator may then select a new record number or may use $\mathrm{ESC} / \mathrm{CR}$ followed by " $\mathrm{X}$ " to return to INIT OPTIONS level. Example 8 shows a sample of a printout utilizing the metro option. 
EHPN FLAPM ENT

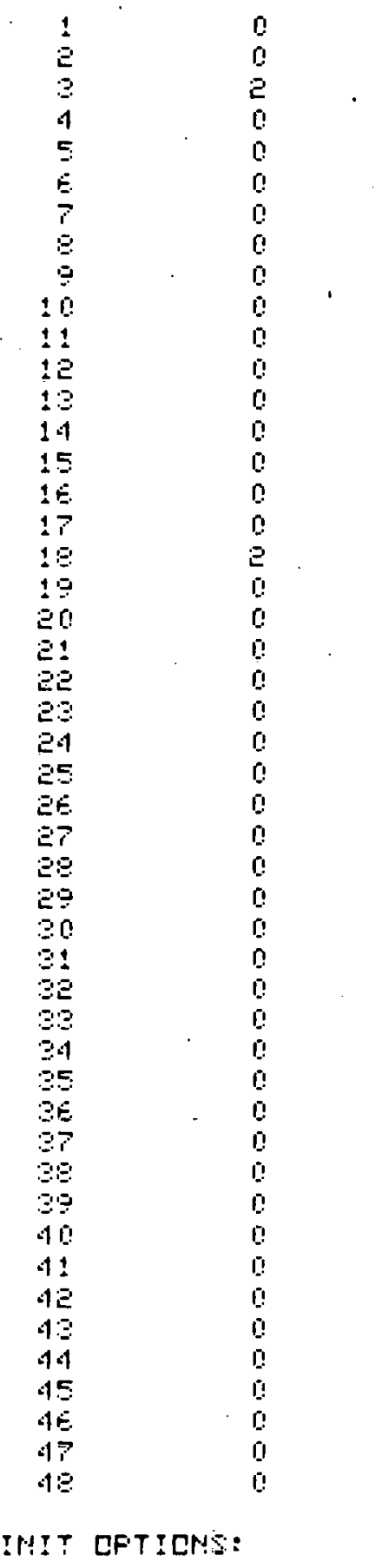

Example E-7

39 
ENT

IHIT CFTICNS:

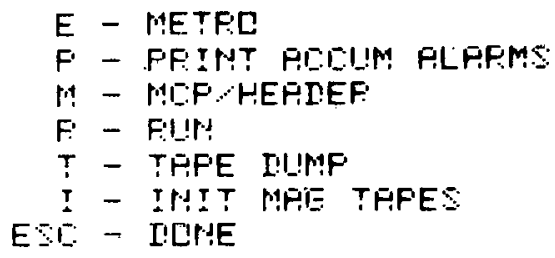

Example E-8 


\subsection{Tape Dump}

The tape dump option is used to print out the digital information on a data tape or other test tape and to find out by reading the printout if recording is taking place properly. It is not possible to do any field data reduction of an analog tape, but through the tape dump routine the operator can gain some assurance that the data are being properly recorded onto the magnetic tape. The tape dump routine also has a subroutine for checking for errors on the digital tape that has had a special encoded digital sequence recorded on it. The operator types " $T$ " on the keyboard when the program is at the INIT OPTIONS level and starts the tape dump sequence. The tapes must be properly loaded onto machine 1 and be at the load point of the program in order to operate. The operator enters the start file number of the digital tape that is to be read. If bit 2 is down, the program will proceed to ask for the next record number and enter a normal tape dump routine. In this normal routine flow, as indicated in Figure 4, the tape will completely print that record unless it is terminated. If the record printing is completed, typing "X" on the keyboard will return the program to the INIT OPTIONS level. If the operator chooses to terminate the printing without going back to the INIT OPTIONS level, he may do so by moving bit 1 up. The program will check for the position of bit 1 and ultimately terminate the printing so that the operator may select a new record number to print out. If the tape being read is one that has been generated under the error detect format in the DIAG2 program, bit 2 is switched up and an error check routine is instigated. The program will print out the errors found by the computer in the recording on the digital tape. The operator, as indicated by the flowchart, has the same options of terminating the program on error checking as he did on terminating the printout of data from a data tape.

Example 9 shows a sample printout of the tape dump options available to diagnose the program difficulties. The printout is in octal values of the binary bits loaded upon the digital tape. All the information is stored on seven tracks; six contain digital data, and the seventh is parity and is not printed out. Since each of the octal values corresponds to a data word that had been output by the Memory Controlled Data Processor, it is possible to read the tape dump and determine that the format is being properly constructed by the Processor. A good point to begin is always with the location of the sync words which appear as $76,57,14,40$. 
IH!T CFTICHS:

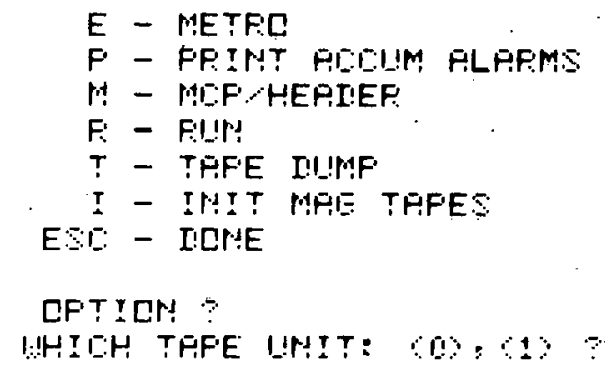

Example E-9 


\section{0 Program Execution and Operation: DIAG1/DIAG3 Program}

The DIAG1/DIAG3 program must be loaded from tape if any other program is resident in the computer. If the program has been previously loaded, it can be reactivated by entering $376_{8}$ on the Nova panel and doing stop, reset, and start functions with the appropriate switches on the front panel. After the computer indicates that the program has been loaded, the operator can type " $\mathrm{X}$ " on the keyboard and move the program to the diagnostic menu level. Figure 5 shows the flowchart for the DIAG1/DIAG3 program. As indicated by the flowchart, the program can then be returned to the load point by exercising ESC/CR on the keyboard. After typing "X" on the keyboard, the program will respond with the diagnostic menu which indicates the various test that may be performed to determine whether a subsystem is operating correctly. The six tests in DIAGI are Time Code Translator, Bilevel, Television, Calibrate, Memory Controlled Processor, and Mass Memory Formatter. Example 10 shows a printout of the diagnostic menu and a TCT test.

\subsection{Time Code Translator Test}

The Time Code Translator check is run to assure that the Nova 2 program is receiving time properly from the lime code generator. The test is started by typing $1 / \mathrm{CR}$ on the keyboard. The computer program will respond with a printout of the time when the program began. It will then move to drop in sync with its test procedure. The next time will be printed out slightly later than the first time. Following the second time printout, the program will make a time printout every 30 seconds for a total of 10 time printouts following the first time printed by the program. The operator should observe that these time intervals will come 30 seconds apart. When the test is over, the program will automatically return to the diagnostic menu level. Example 10 shows a sample printout from the TCT test.

\subsection{Bilevel Test}

The bilevel test allows the operator to verify that bilevel channels can be read by the computer. The bilevel routine is activated by typing $2 / \mathrm{CR}$ on the teletype. The operator may then type $\mathrm{R} / \mathrm{Cn}$ to read any active bilevels, If none are present, none will be printed, Any present will be printed, and the routine will return to the bilevel test menu. Typing "I" will clear any registers of bilevel data and they will wait for an interrupt. Whenever an alarm is triggered, it will trigger the interrupt feature of the interface and the computer will print the bilevel channel that triggered the alarm. This interrupt feature is not used in the existing software but allows the check to be done at this time to verify the incoming bilevel channel signal. By typing C/CR, the operator can clear any bilevel channels. To return to the diagnostic menu level, type ESC/CR. An exariple of a bilevel test is shown in Example 11. 


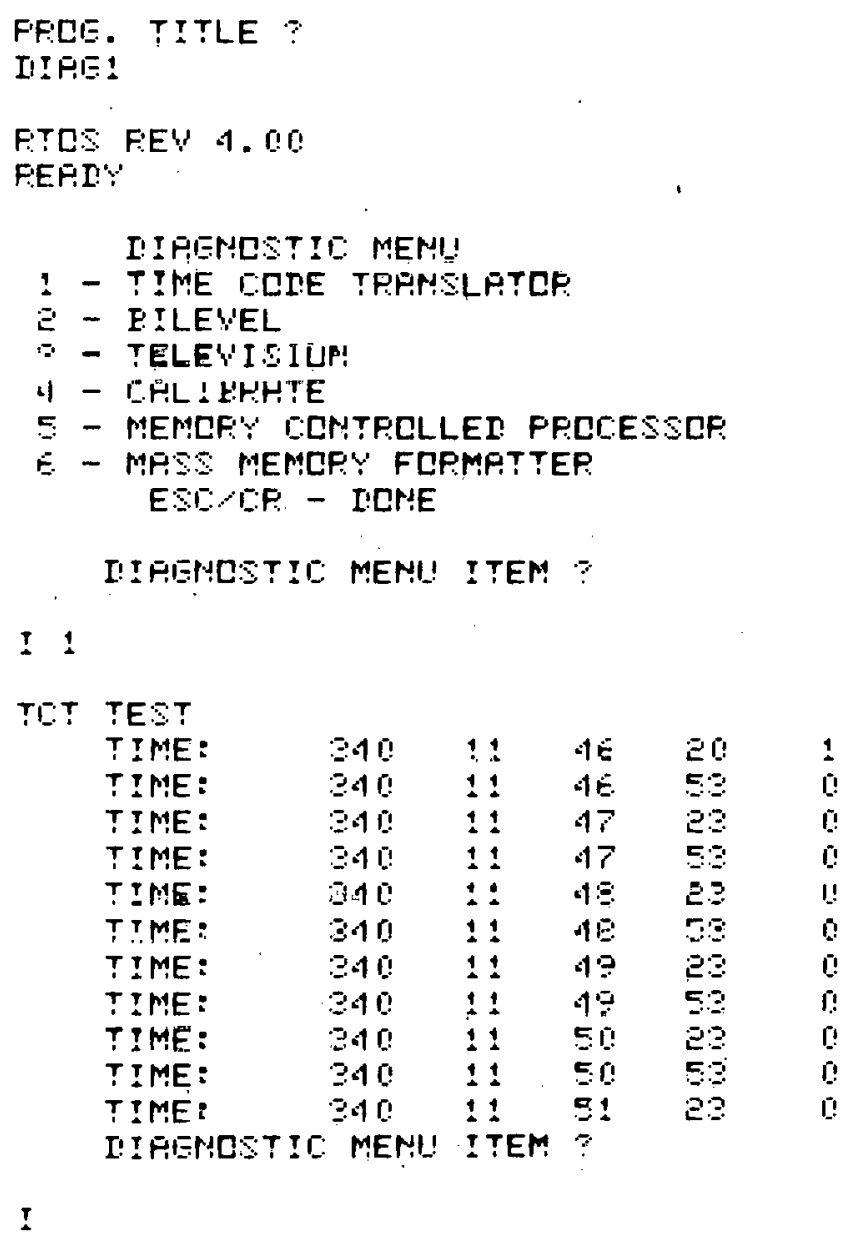

Example E-10 
$\Xi$

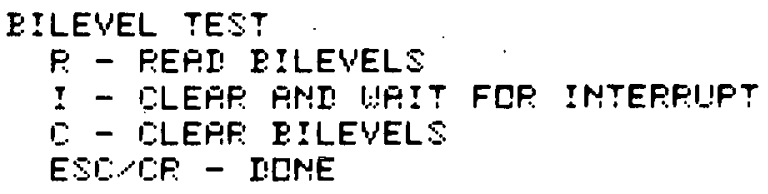

I $\mathrm{F}:$

FI:TI'YE EILEWELS

$$
\begin{array}{ll}
\text { I } & \text { I } \\
\text { I } & \text { I: } \\
\text { I } &
\end{array}
$$

Example E-11 


\section{3 Camera Test}

The camera test routine allows the operator to verify that the computer has control of the video switcher and video tape recorders. By typing 3/CR at the diagnostic menu level, the camera test program will be activated. Example 12 shows a printout of the camera test. Thc printout capability is not as important as observing the equipment during the test. By using the field of view command, run tape command, and stop tape command, the operator can individually control the functions of the tape machine, video switcher, and character inserter. While running these tests, observe the following things: first, that the character specifying the field of view changes in the video being displayed on the monitors, and second, that the cameras switch to cover the proper alarms when triggered by the appropriate bilevel channel. During the test, the operator should also verify that the tape machines can be turned on and off by entering the appropriate commands from the keyboard. With the computer program operating in this rn!line, it iv possilile to delemine that the proper signals are being sent and received from the video subsystem. Tixamplc 13 slıuws a printout of the camera test and indicates the status replies to various commands sent to the video subsystem.

\subsection{Calibrate Test}

Thc calibrate test is used to check the capability of the system to send proper calibration signals to both the Environmental Data Processor and the analog-to-signal conditioning interface. The operator can type $4 / \mathrm{CR}$ at the diagnostic menu level to bring the calihrate test routine into uperation. The S/CR command will switch the input channels to the digital-to-analog output from the computer. The $\mathrm{R}$ command will switch the inputs back to the data or run input position. As indicated in the flowchart in Figure 5 , the sal swlich should always be set to the "cal" position before attempting to enter cal values. After entering each command of $S$, $R$, or $C$, the program will return to the calibrate test menu level; thus, the operator can enter a number of cal values and chock to see that the inputs to the various data channels are changing values. The cal outputs vary from -10.24 to +10.24 volts. The operator enters the appropriate voltage, and the computer will respond with a binary value that it has sent to the digital-to-analog converter. At the end of a test, the input to the channels should always be returned to their data position by typing $R / C R$. Type ESC/CR to return to the diagnostic menu level. Fxample 13 shows a sample printout of a callbrate test.

\section{5 Memory Controlled Processor Menu}

To obtain program control at the Memory Conleulled Frocessor level, the operator types $5 / \mathrm{CR}$ on the teletype. The computer will reply by printing out the various suboptions available to the operator. This test program is used to diagnose problems and to verify the operation of the Memory Controlled Data Processor and its associated Dataram memory. 


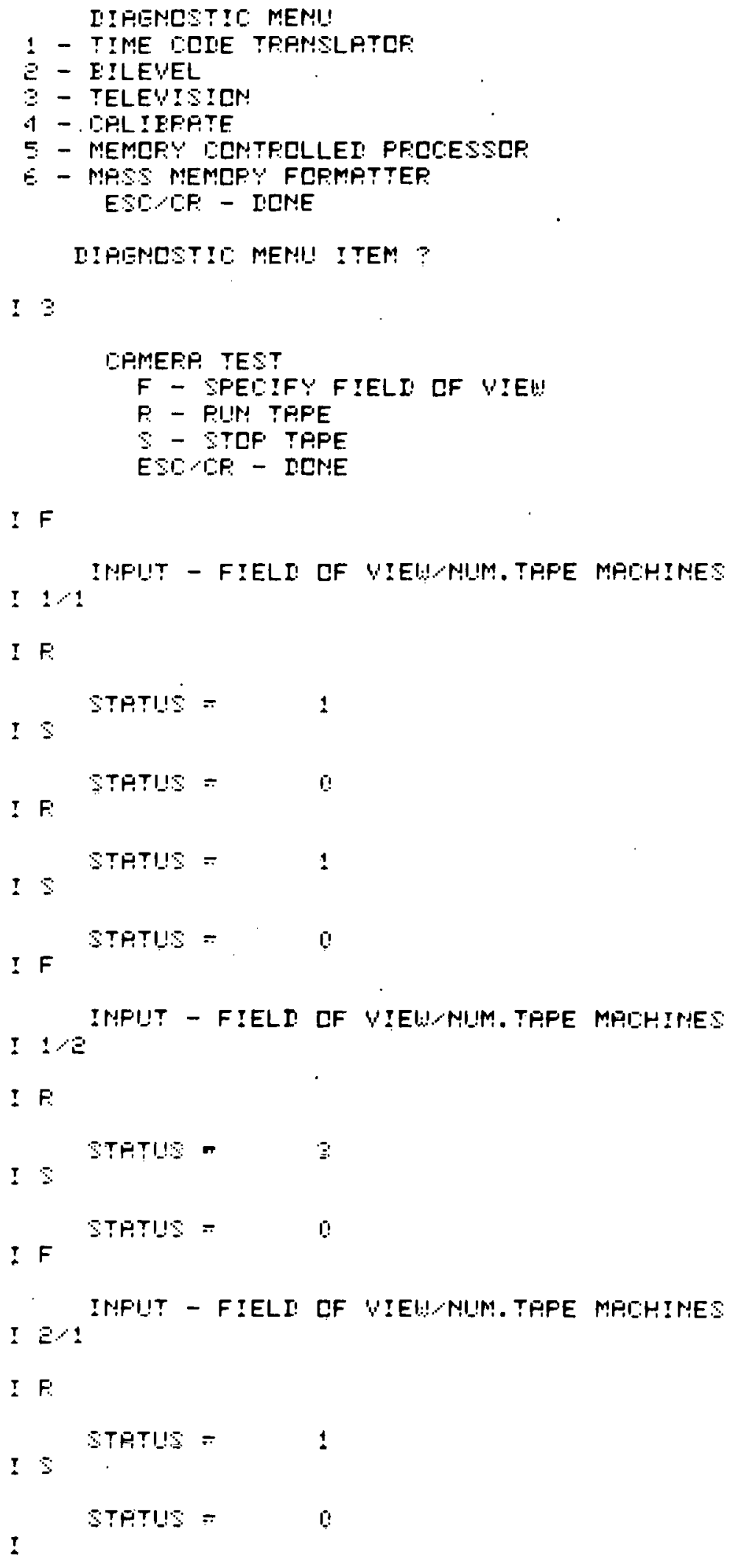

Example E-12 
I 4

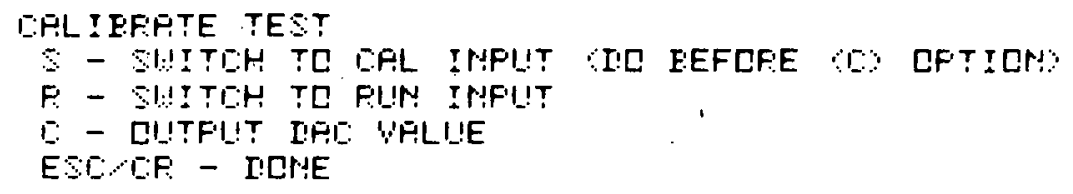

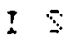

? 1

ERL YPLLIE =

$I E$

195

I

T:PL WHLIE -

I

11.44

I $\mathrm{C}$

I $-e^{\text {EPL WELIIE }=}$ 60

I

EOL YHLIE =

I -7.5

ㄴ:?

I :

ERL YRLIIE =

I $10.2 \mathrm{E}$

1770

I $\mathrm{F}:$

!

Example E-13 


\subsubsection{Output Command and Read Status -- The Memory Controlled Data Processor has}

certain functions that are directly controlled by the Nova program. These functions are listed in the command menu and are Halt, Run, Cal Start, and Cal Stop. The operator may enter any of the commands 0 through 3 and see that the correct status reply is received, which indicates that the circuitry has received the command and returned that particular status to the Nova. The operator can also observe the lights on the front panel of the Memory Controlled Data Processor and note that they are following the commands issued from the teletype keyboard. As shown in Figure 5 , the operator must type $1 / C R$ to get to the command menu level. At that level, he may type again any number, 0 through 3 , followed by the $C R$ to achieve the control function. At the end of that operation, the program automatically returns to the Memory Controlled Processor level.

\subsubsection{Memory Test -- The memory test is a check of other command functions and the} memory's capability to be written and read by the Nova. The memory test is begun by typing $2 / \mathrm{CR}$ on the teletype. The program requests the octal memory value, the start address, and the end address plus 1. Those values are entered via the keyboard, and the program to test the memory is immediately executed between the addresses indicated. The program will write the value into memory and then read the value out and check to verify that the two are identical. The number entered to test the memory must be something less than the octal number 177777 . This requircment exists because the memory is 16 bits wide by 4096 addresses. If the test fails at any given address, that address will be printed out under the column "Address Errors". If no address errors appear, the program will type "Memory Test Done" and return to the menu level.

\subsubsection{Memory Dump -- The memory dump enables the operator to read a value in any} address of the memory. The memory dump routine is entered by typing $3 / \mathrm{CR}$ on the keyboard. The program requests that the operator enter the begin and end addresses that he wishes to have read from the memory. The teletype will output the values and then return the program to the menu level.

Both the memory test and the memory dump items on the MCP menu can enter long printout loops which may need to be terminated by the operator before thcir completion. These loops can only be terminated by using the stop switch on the computer panel. The program may then be reloaded from the $376_{8}$ address from the front panel. Example 14 shows the options and sample printouts for exercising the Memory Controlled Processor menu.

\section{6 Mass Memory Menu}

The Masg Momory menu is set up to interrogate the 2.3 megabit memory associated with the output from the Memory Controlled Data Processor. The program routine 1s entered by typing 6/CR on the keyboard. The computer program responds with a list of the Mass Memory menu options, Through the software routines located under the Mass Memory menu, the operator can check the functions of the Mass Memory and the Mass Memory Interface. 


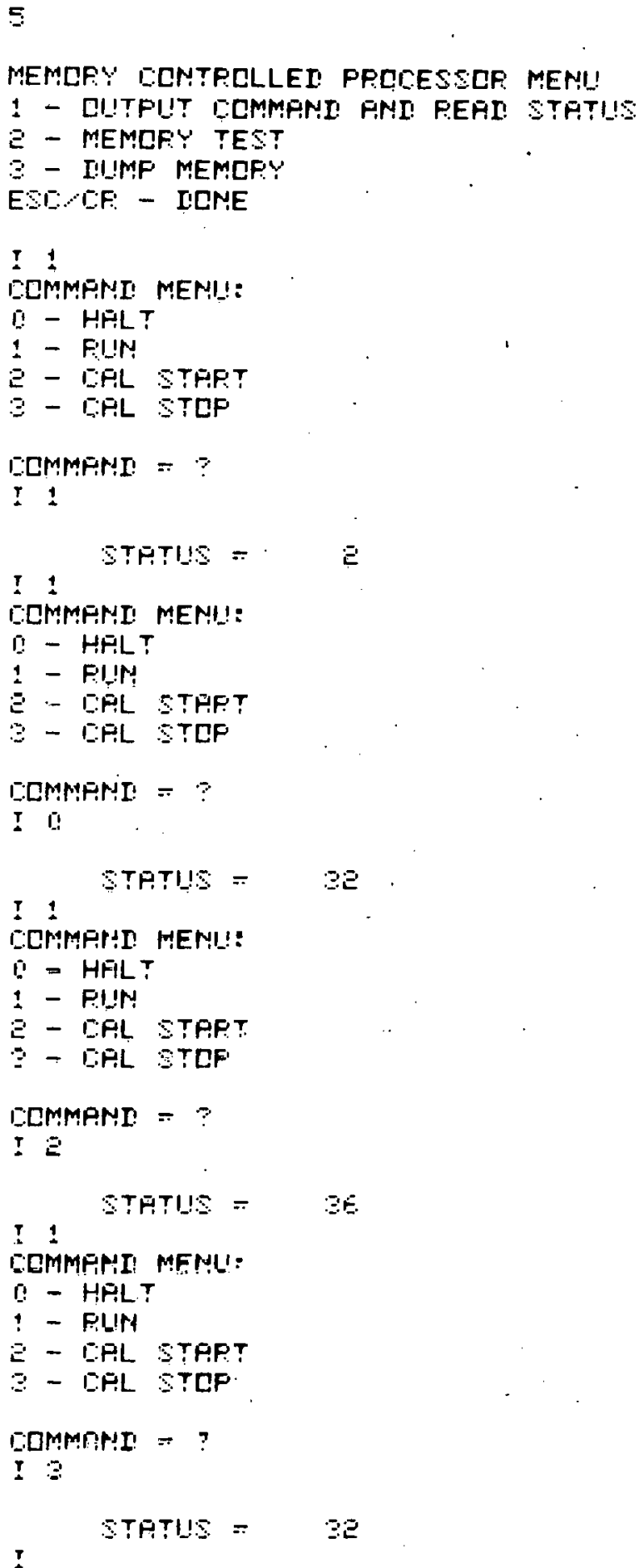

Example E-14 


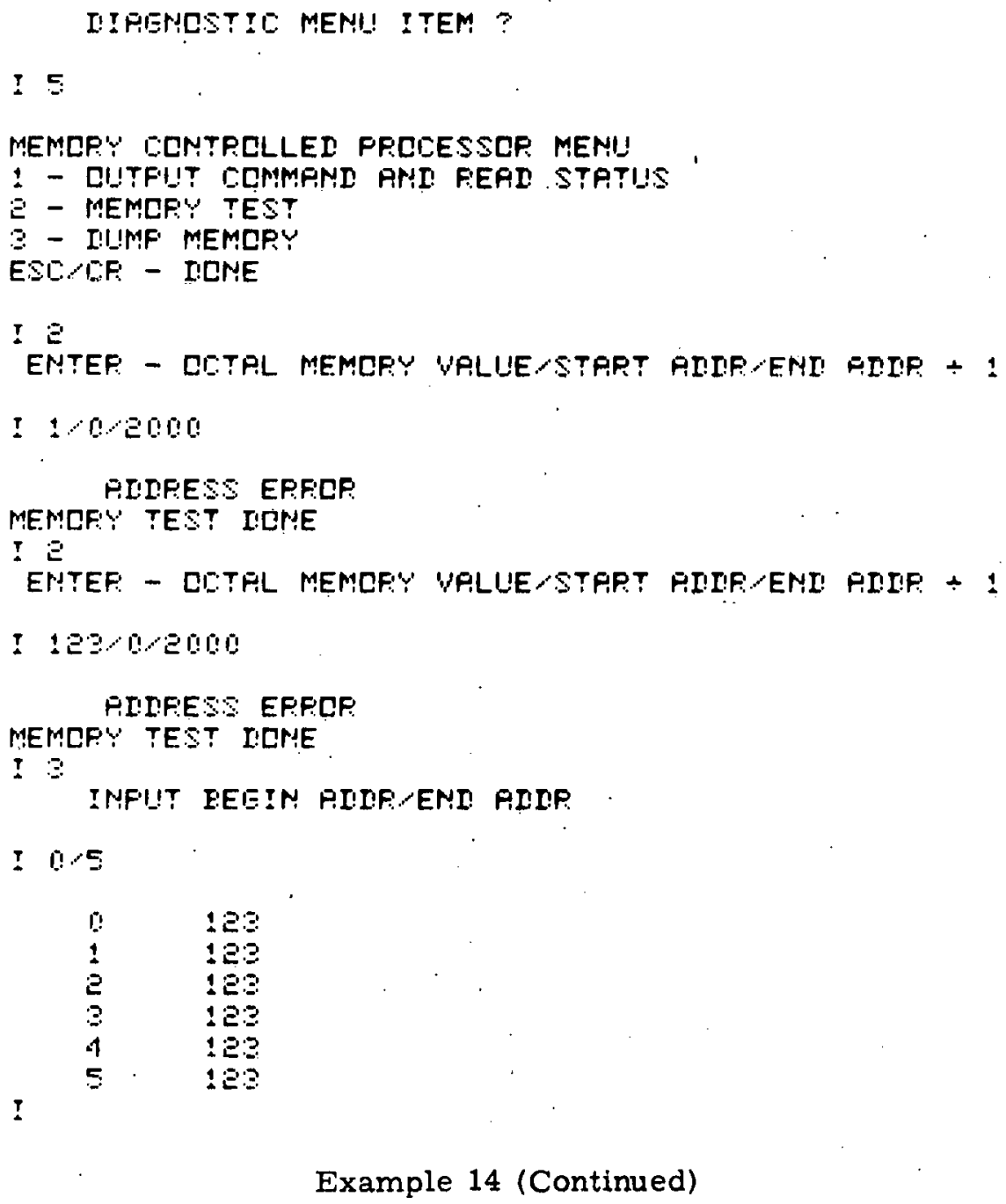

Example 14 (Continued) 
6.6.1 Write/Read Memory -- This routine has the capability of writing known patterns into the Mass Memory and verifying that that pattern has been written. Typing $1 / \mathrm{CR}$ on the keyboard will cause the program to respond and ask for the octal memory value to load along with the start address and the end address. The Mass Memory has 65, 536 addresses that each contains 36 bits of data. The computer will load the designated value and check to see that it has been properly written into the memory by performing a read cycle. If there are any address errors, they will be printed out. When the test is completed; the routine will type "Memory Test Done". See Example 15 for illustrations. Because the Nova has to reformat and repack data for loading into the Mass Memory locations, there are some restrictions upon the values that can be entered. To write an all zeros pattern, 0 is simply entered. To write an all ones, 37477 must be entered. In the pattern shown of five octal digits, there are some restrictions which must be observed. For example, only $0,1,2$, or 3 can be the first digit. The second digit can be any octal number to 7 . The third can be only a 0 or a 4 . The remaining two dicito saln ly any ootal digit, 0 through 7 , Tlie reason for these regtrictions can be best be explained by the table below:

16 Bit Nova Word in Octal

X XXX XXX XXX XXX XXX

Only 12 Bits are used (2 6-Bytc Words) for tape transfers

0 0XX XXX X00 XXX XXX

2 6-Byte Words (XXX XXX) (XXX XXX)

6.6.2 Read Status Registers -- This option allows the operator to read the status registers in the Mass Memory Interface. The routine is entered by typing $2 / \mathrm{CR}$. The teletype will printout STAT CA CA-N Nova ADDR. STAT stands for the statuo word and. ls represented by status bits which are read as a five digit octal number in the printout under STAT. The bits and their meaning ale as follows: bit 15, crror; bit 14, transfer çompletc; bit 13, unpackıng buffer; bit 12, unpacking constant; bit 11, hlnn! tranofer complete; bit 1U, always low; bit 9 , under flow; bit 8, over flow; bit 7 , memory busy; bit 6 , memory write; bit 5 , memory read; bit 4, low. CA stands for current address and is a five digit octal number indicating the current status of the address counter. CA-N represents the current address minus an $\mathrm{N}$ velue and io alsu a flve algit octal indication of that register. The Nova address register is a five digit representation of the Nova address register (see Example 15).

6.6.3 Write Registers -- The write register option permits the operator to write any combination of bite into tlie slatuo regisler and the Nova address registers in the computer. This option is entered by typing $3 / \mathrm{CR}$. Upon completion of the write register function, the program returns to the Mass Memory menu level. The operator may check to verily that the proper values have been inserted into the registers by doing a read status of the registers (ape Examplẹ 15).

6.6.4 DMA Realtime -- The DMA realtime option is exercised by typing $4 / \mathrm{CR}$. The computer will printout "Word Count Equals". The operator may now enter a word count for the computer to dump. After typing CR, the computer will print Memory Controlled Data Processor outputs for the selected number of words (see Example 15). 
I

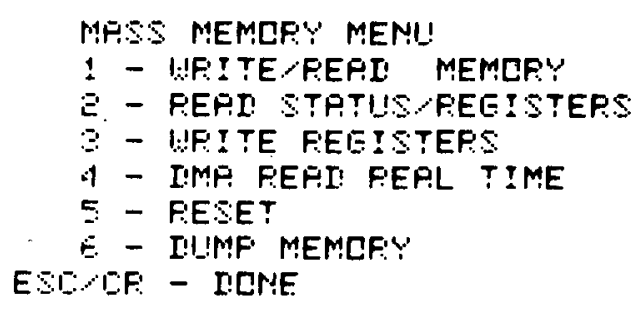


IIAERTCSTIE MENI! ITEM $?$

I

MASS MEMCFY MENI!

1 - IUFITE PEAD MEMLPY

Z - FEFI STPTUS PEGISTEPE

Z - IIFITE REETSTEPS

4 - IMMA READ PEFL TIME

5 - FESE?

E - IIIMP MEMLPY

ESCRP - IDNE

I

INFUT - EEGIM PIDP /ENI RIDF:

I 000

\begin{tabular}{|c|c|c|c|c|c|}
\hline 0 & $7 \mathrm{~B}$ & 79 & $P 4$ & 78 & TE \\
\hline 1 & $!$ & $z$ & 2 & 4 & 5 \\
\hline$\Xi$ & 7 & 10 & $1 !$ & 10 & 13 \\
\hline$\Xi$ & 15 & 18 & 17 & 20 & E! \\
\hline 4 & $\theta 0$ & 24 & 25 & $2 \epsilon$ & 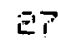 \\
\hline 5 & 31 & 92 & 32 & 34 & 85 \\
\hline$E$ & 97 & 40 & 41 & $4 E$ & 43 \\
\hline 7 & 45 & 16 & 47 & 50 & $5 !$ \\
\hline$\because$ & 53 & 54 & 55 & 5 & 57 \\
\hline ج & $\leqslant 1$ & $\mathrm{da}$ & 50 & 사 & $E$ \\
\hline 10 & 57 & 70 & 71 & 72 & 73 \\
\hline $1:$ & 75 & 78 & 0 & ! & I \\
\hline 12 & 4 & 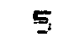 & $E$ & 7 & 10 \\
\hline 13 & $1 \bar{z}$ & 13 & 14 & 15 & IE \\
\hline 14 & 20 & E! & $2 E$ & 20 & 84 \\
\hline 15 & $E \epsilon$ & 27 & 20 & $2 !$ & 3 \\
\hline 16 & 34 & 35 & 3E & 27 & 40 \\
\hline 17 & 42 & 43 & 44 & 45 & $4 E$ \\
\hline 18 & 50 & $5:$ & 50 & 5 & 54 \\
\hline 19 & $5 F$ & $5 ?$ & 60 & 61 & $C^{-1}$ \\
\hline 20 & $E .4$ & 65 & $E \in$ & $E .7$ & 70 \\
\hline
\end{tabular}

Example E- 15 (Continued) 
6.6.5 Reset -- The reset option is used to clear the Mass Memory. Typing 5/CR at the Mass Memory menu level causes the Nova software program to reset the memory and to write $0^{\prime} s$ in all bit positions (see Example 15).

6.6. 6 Dump Memory -- The dump memory option is utilized by typing 6/CR. The computer will ask for the begin address and the end address. Type the two 5-digit octal number addresses separated by a slash and the computer will printout the data in the memory, in a column format, for the total number of addresses indicated. To interrogate only one address, use the same address in both the beginning and end address locations. This will result in only the data for that address being typed out.

If the operator wishes to terminate the printout of a read/write cycle on the memory or the memory dump, he may do so by operating the "stop" switch on the front panel of the computer. 'This will terminate the program operation. To reinitiate it, the operator must enter $376_{8}$ on the front panel data switches, and push first the reset switch and then the program start switch. Samples of printouts for Mass Memory menu are shown in Example 15.

\subsection{DIAG3 OPTION}

The illustrations covered thus far apply to the DIAG1 program. If the DIAG3 program is ... loaded, then one additional option is available to the user. The additional option is the metro tape dump. A printout of the DIAG3 metro option is shown in Example 16. To call up the metro dump, type $7 / \mathrm{CR}$ on the teletype. The operator may now enter file numbers and record numbers to print out data from a metro tape. For a complete description of the metro option, see paragraph 5.1.4. 
FF:CE. TITLE

I!IPE:S

FTCS F:EY A 1 . DI

F:EFIY

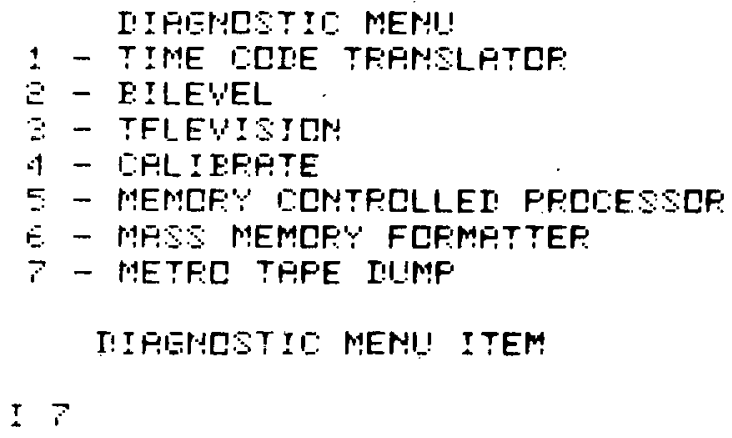

Example E-16 


\section{0 Program Execution and Operation: DIAG2 Diagnostic Program}

The DIAG2 program can be loaded from tape or, if previously put into the computer, can be restarted from $376_{8}$. Type " $X$ " on the keyboard to bring up the diagnostic menu for DIAG2. The diagnostic menu consists of "Run, MCP/MMF without tape", an option which permits the user to pass data through the system without recording it on tape, and "Run MCP/MMF with tape", an option that will cause the digital tape to record the data. The third option is a tape dump which allows the operator to play back any recorded data from option 2. See Example 17 for a printout on the options available for DLAG2. Figure 6 is a flowchart that breaks down the various options and the operator control for those options.

\subsection{Run MCP/MMF Without Tape}

The run without tape option routine is called up by typing $1 / \mathrm{CR}$ on the keyboard. When the program is at the run MCP/MMF without tape menu level, the operator may select one of three control options. All three of these options lead to a similar set of branch instructions at a lower level that relate to the dumping of data on the teletype.

7.1.1 Data Run with External Signals -- The first option allows the operator to go directly through to the dump or no dump levels and to load the appropriate parameters into the program. Choosing this option will set up a data run and allow the input amplifiers to remain connected to external data sources. This option is exercised by typing $1 / \mathrm{CR}$ on the keyboard.

7.1.2 Data Run with Cal Signals -- By exercising this option, the operator can choose to input through the calibrate system a fixed voltage onto all of the channels. Type $2 / \mathrm{CR}$ on the keyboard, and the computer program will come back and ask for a cal value $(-10.24$ to +10.24$)$ to be input into the system. After the value has been selected by the operator, the program will proceed to the dump selection level. The data run achieved in this manner requires a data format as in a real data collection. Using the system in this manner allows the operator to use the computer as a signal source for all the channels and to input a known value for each of the channels called up in the format.

7.1.3 Cal Run with Cal Signals -- This option is similar to the second option except that in addition to putting cal values on all channels, the Memory Controlled Data Processor is run in a calibrate mode which causes it to output only master frames in the data stream. This option is activated by typing $3 / \mathrm{C}$ and cntering the calihrate values. The option also proceeds to the same dump option as the previous two selections.

7.1.4 Dump Options -- The dump option level further branches into three additional choices for the operator. He may choose "no dump", in which case the Memory Controlled Processor, the Mess Memory Interface, and all associated hardware are set into a "Run" mode which will permit diagnostic work and troubleshooting on the system hardware. The other dump options will print the data being output by the MCP. 


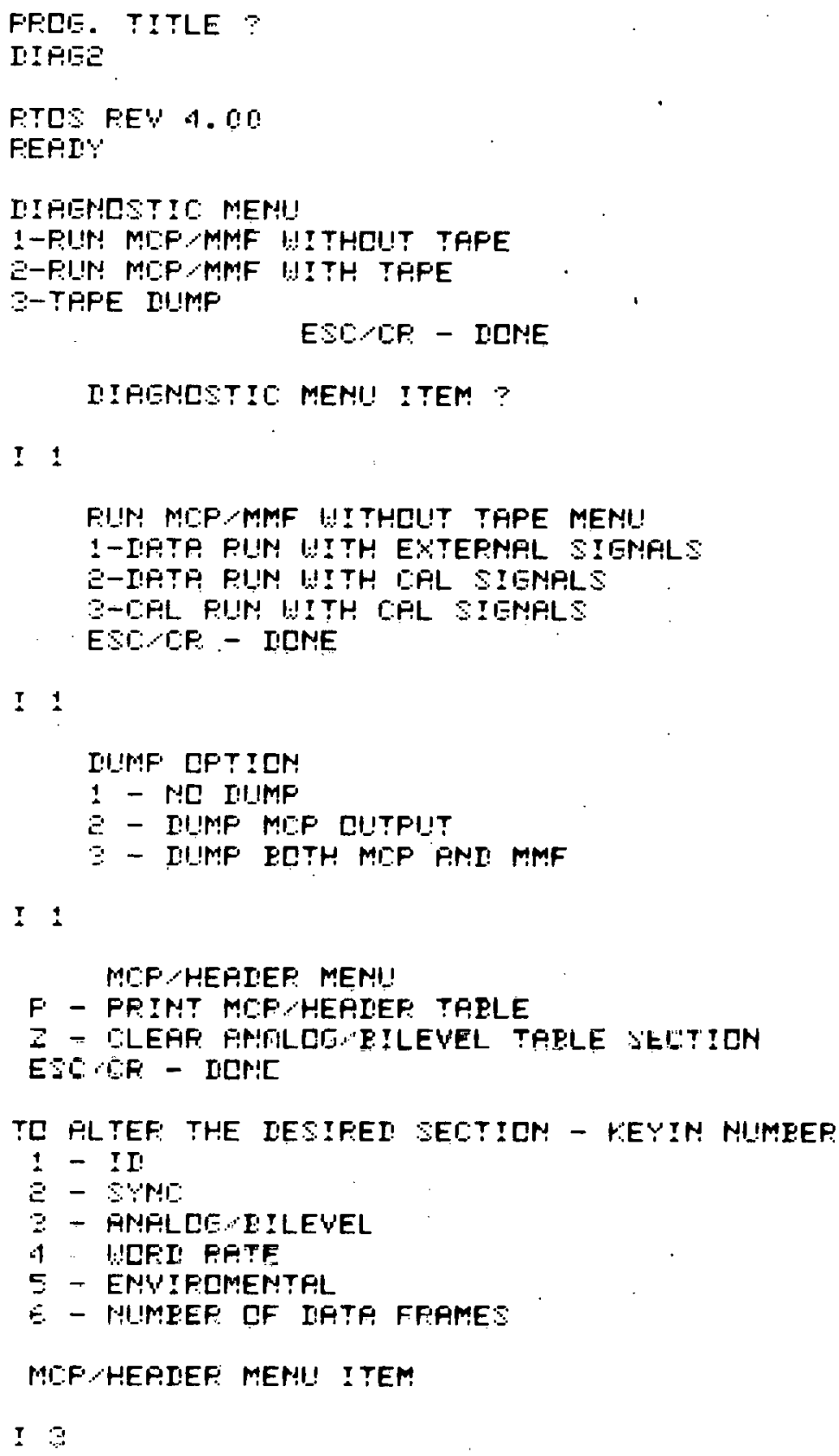

Example E-17 
7.1.5 No Dump -- The no dump option is entered by typing 1/CR on the keyboard. At this point, the operator may proceed to load any desired format for the Memory Controlled Data Processor's operation. See the "Alarm" format instructions in paragraph 5. 1. Once the appropriate format has been loaded into the program (this is required only once in the diagnostic menu routines), the operator may type ESC/CR to activate the "run" option in this test situation. The computer will printout the coded instructions and addresses that are placed in the memory of the Memory Controlled Data Processor and will place the Processor in the run option. It will remain in the run option until any character in the teletype is typed. The program will then halt the Processor and stay at that level until the operator types ESC/CR to return to the "Run MCP/MMF without Tape" menu option level (see Example 18).

7.1.6 Dump MCP Output -- The dump MCP output may be entered by typing 2/CR. The program responds by asking for entries to the MCP header menu. This option may be loaded per the instructions contained under the "Alarm" program (paragraph 5. 1). After the Processor has been programmed, typing ESC/CR will activate a "run" mode for the system. The program will print the format instruction codes, addresses, and exit to collect data. It will print MCP data on the teletypc, and return to the "Run MCP/MMF without Tape" menu option level (see Example 19).

7.1.7 Dump Both MCP and MMF -- The third option allows the operator to select a data dump on the teletype of information from both the MCP and MMF. The option is activated by typing $3 / \mathrm{CR}$ on the keyboard and, if required, entering the MCP header information per instructions contained in the ALARM routine (paragraph 5.1). Once the format information has been entered into the program, the operator may type ESC/CR and the computer program will print the format instructions, address, and data printouts representing both the MCP and the MMF. At the completion of the print out, the program will exit and return to the "Run MCF/MMF without Tape" menu option level (see Example 20).

\subsection{Run MCP/MMF with Tape}

The sernnd option on the diagnostic menu in DIAG2 is entered by typing $2 / \mathrm{CR}$ from the diagnostic menu option level. "The program will print a "Run MCP/MMH' with Taje" monu, offering the operator three options from which to select. The first option, a "Data Run with External Signals", is used to collect data on tape and to verify the operation of the system with the digital tape recorders. The second option, the "Data Run with Cal SIgnals", is used to verify the same type of operation except that the values inserted into the data stream are controlled by selecting a calibrate value for the analog chamiels. The third option for this part of the program io the generation of an error detection format. The error detection format loads a special walking bit pattern in the Memory Controlled Data Processor which counts from 0 to 70. Thio pattern ran be sent through the regular process of data storage, retrieval, written on tape, and recovered from tape to test the complete operation of the system and check for bad addresses in the Mass Memory that contain incorrect data. Since the pattern is sequential, any dropouts or wrong addressing is aleo detecter by the program. 
FHFLLEEILEYEL SEITICH. .

I $E$

I FPF15E $\$ 0.24 \%$

I

MIF HEFIIEF MENI! ITEM

I 5

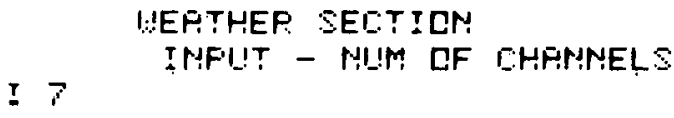

I

Q 1EDORE

1 1 100507

$2 \quad 200014$

3 it!!!

1 EE

514006.4

E. EI!UE

7. 150060

$8 \quad 17416$

- 227777

10 1.:00

11110067

204: 150000

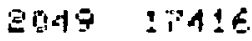

EDSO 127777

Eos: : 00000

E05e 170070

INFIT ANY GHAFARTEP TC STCF

I

!

Example E-18 
I 1

FILI! PILF MPIF UIITHCLT TPPE MENIL

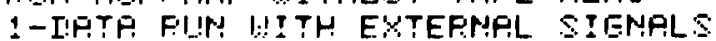

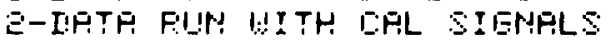

S-IFL FILH UITH ERL SIENALS

EOLEF: - IICHE

! !

I!IMF CFT ICH

1 - NC IIIIMF

E - IIUMAF MEP DI!TPI!T

Z - IUMP FETH MIOF PHII MMF

!

MOF HEFIEF: MEPHI!

F' - FFIMT MICF HEFIER TFELE

Z - ELEFF PNALLE EILEVEL TPELE SECTICN

EQLE: - IICHE

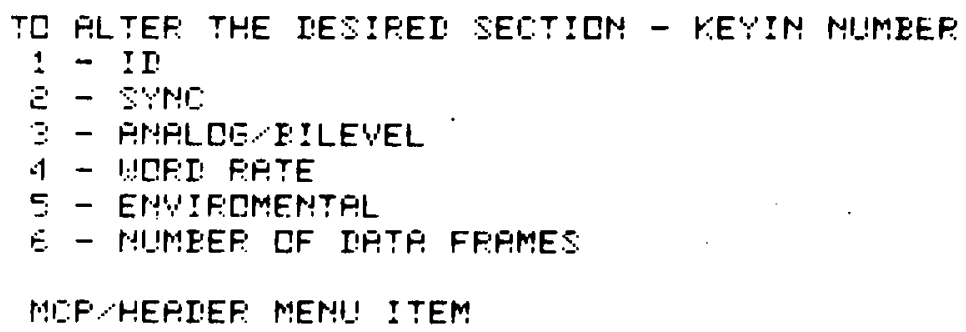

I

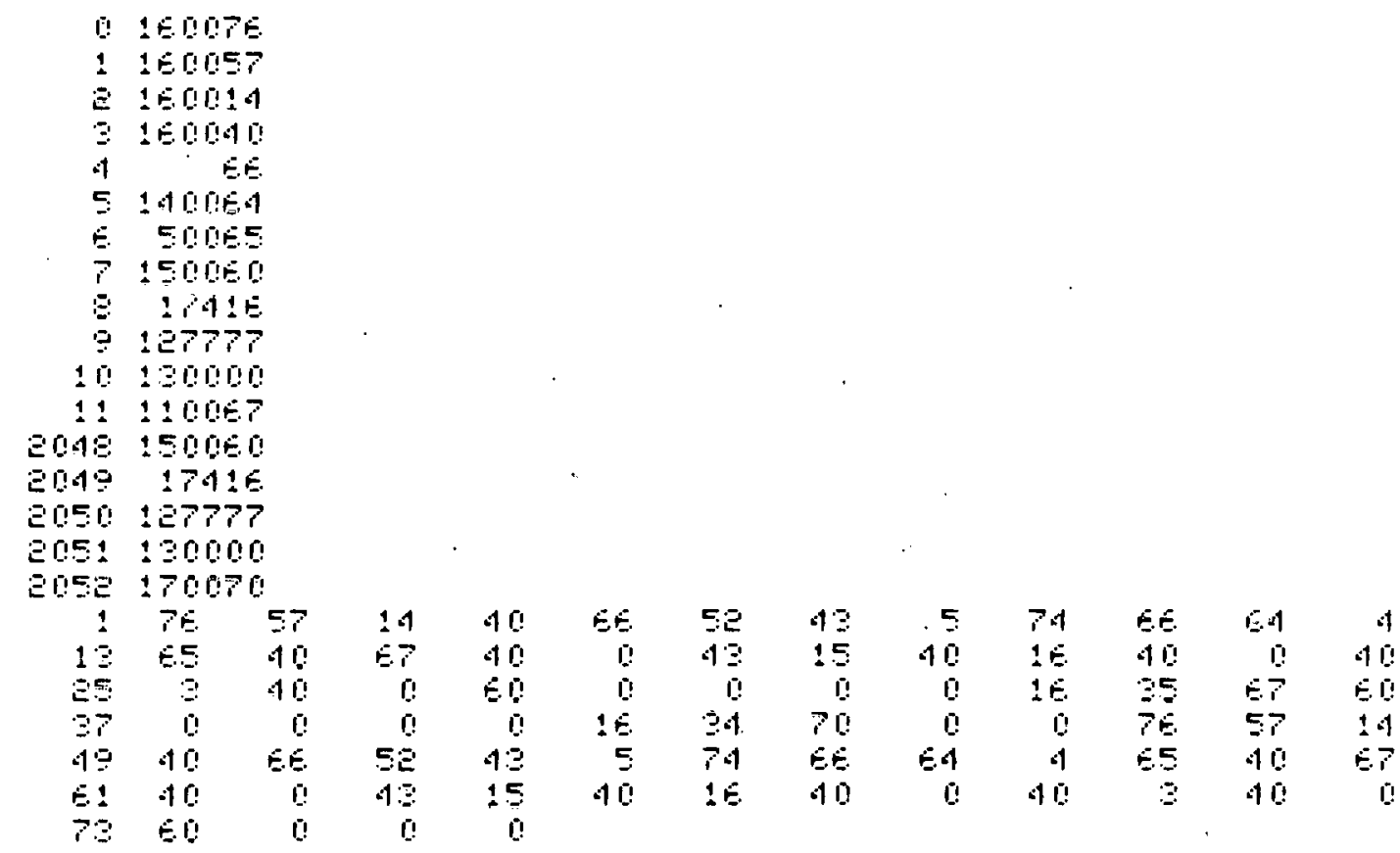

Example E-19 
I!I!MP CFI:TC!!

1 - P.D LILIMF

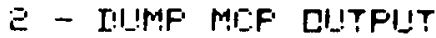

$\because$ - IU!MF ELTH MLF FHI MMF

I

MEF HEFIIEP, MENI!

F - FFIMT MIF LHEFIEP TPELE

Z - DLEPF PNALCE EILEVEL TPRLE SETTICH

ESELF: - IICNE

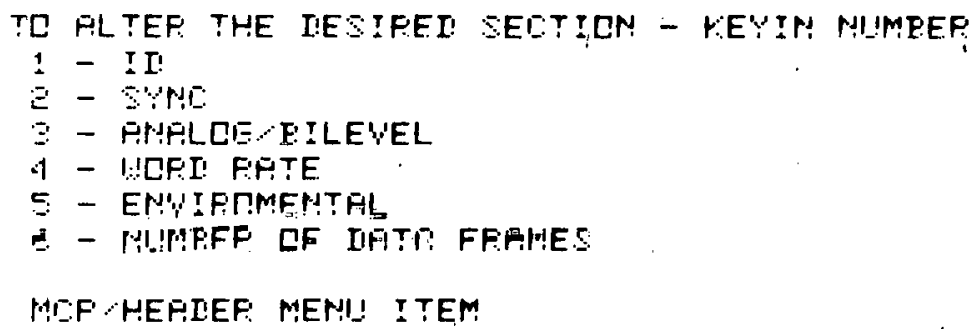

?

\begin{tabular}{|c|c|c|c|c|c|c|c|c|c|c|c|c|}
\hline 0 & \multicolumn{2}{|c|}{ QEOQPE } & & & & & & & & & & \\
\hline 1 & \multicolumn{2}{|c|}{$2 E \operatorname{QOS}$} & & & & & & & & & & \\
\hline$E$ & \multicolumn{2}{|c|}{$2601 ! 4$} & & & & & & & & & & \\
\hline$\because$ & \multicolumn{2}{|c|}{$1 E 0100$} & & & & & & & & & & \\
\hline 1 & \multicolumn{2}{|c|}{$E$} & & & & & & 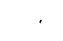 & & & & \\
\hline 5 & \multicolumn{2}{|c|}{140004} & & & & & & & & & & \\
\hline$E$ & \multicolumn{2}{|c|}{50055} & & & & & & & & & & \\
\hline 7 & \multicolumn{2}{|c|}{15000} & & & & & & & & & & \\
\hline$\Xi$ & \multicolumn{2}{|c|}{17416} & & & & & & & & & & \\
\hline בִי & \multicolumn{2}{|c|}{$1 E 7 \%$} & & & & & & & & & & \\
\hline 10 & \multicolumn{2}{|c|}{ : 21000} & & & & & & & & & & \\
\hline 11 & \multicolumn{2}{|c|}{ \pm 10 OUE } & & & & & & & & & & \\
\hline E04E & \multicolumn{2}{|c|}{$150 \mathrm{nog}$} & & & & & & & & & & \\
\hline Е & \multicolumn{2}{|c|}{17415} & & & & & & & & & & \\
\hline $205 n$ & \multicolumn{12}{|c|}{ :อフフ77 } \\
\hline 2051 & \multicolumn{3}{|c|}{150000} & & & & & & & . & & \\
\hline E05: & \multicolumn{12}{|c|}{ \pm 79079} \\
\hline 1 & TE & 57 & 14 & $4 !$ & $E E$ & 5 & 43 & $E$ & 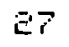 & $E 0$ & $E .1$ & 1 \\
\hline 10 & $E$ & 10 & $7:$ & 4 & 4 & 13 & $E$ & 40 & 17 & 40 & 0 & 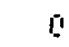 \\
\hline E5: & $\Xi$ & 10 & 0 & $E$ & 0 & 5 & 1! & $i$ & $1 E$ & 30 & 0.7 & $E 0$ \\
\hline 8 & 0 & i! & 0 & !! & $1 E$ & 20 & 70 & 0 & !! & $7 E$ & 57 & \pm 1 \\
\hline 15 & 10 & $E$ & 52 & $4:$ & $E$ & 27 & $2 !$ & $E 4$ & 4 & $E$ & 40 & 71 \\
\hline 1 & 10 & 4 & 48 & $E$ & 40 & 17 & 40 & i: & i! & 3 & 10 & i \\
\hline 73 & E & !! & 0 & i! & & & & & & & & \\
\hline \pm & 10 & 5 & $4:$ & ت゙' & $E .1$ & 4 & 65 & 10 & $E F$ & 40 & $\because$ & 40 \\
\hline 12 & 81 & $1 !$ & 17 & $4 \pi$ & 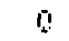 & $41 !$ & 1 & 40 & !! & $E !$ & 0 & 0 \\
\hline 5 & i! & i! & $\vdots \ddot{E}$ & 54 & $E F$ & $E[$ & 0 & 0 & i! & 0 & $1 E$ & $\because 4$ \\
\hline$\because 7$ & 70 & I! & I! & PE & 57 & 14 & 10 & $E E$ & 5 & 43 & 5 & 43 \\
\hline בجִ1:4 & $\Xi$ & $E 4$ & 4 & $E 5$ & 40 & $E 7$ & 10 & $\dot{E}$ & $1 \Xi$ & $E 0$ & 10 & $2 \vec{F}$ \\
\hline$E:$ & 40 & II! & 40 & $!$ & 40 & [! & $E 0$ & 0 & i! & [! & i! & $\pm E$ \\
\hline 73 & 30 & $E F$ & $E 0$ & 0 & & & & & & & & \\
\hline
\end{tabular}

Example E-20 
7.2.1 Data Run with External Signals -- The data fun with external signals is entered by typing 1/CR on the keyboard. Example 21 shows a typical printout. The operator will next select the recording point for the digital data, which may be either load point or may be at the end of an already existing file on the tape. If the format has not been loaded into the program, the operator may accomplish that by entering the "Select MCP Header" menu and changing the values to accommodate the format desired. At the end of proper format programming, the operator will type ESC/CR and the system will load the program and begin the tape sequence. During the tape sequence, the operator may terminate the program by typing "X" followed by ESC/CR to return to the diagnostic menu level. If the sequence is allowed to go to.completion, only ESC/CR is required to return the program to the diagnostic memu level.

7.2.2 Data Run with Cal Signals -- This option is selected by typing 2/CR. The computer will ask for a cal value $(-10.24$ to +10.24$)$ which is entered by the operator. Following the cal value, the program will ask for the load point on the tape. If programming has not been done for the format, the MCP header menu must be entered and programmed for the correct format. See the instructions under the Alarm Programming (paragraph 5.1). When the necessary format information is loaded, the operator will type ESC/CR and the program will begin by loading the MCP format instructions and then will exit to complete the program sequence with the digital tape. The sequence can be terminated at any time by punching $\mathrm{X}$ on the keyboard followed by ESC/CR to return the program to the diagnostic menu level. If the sequence goes to completion, the operator need only type ESC/CR to return to the diagnostic menu level (see Example 22).

7.2.3 Error Detection Format -- The error detection format is selected when the operator desires to check for problems in the memory, data transfer, or digital recording. The error detection format is entered by typing $3 / \mathrm{CR}$ on the keyboard. If the operator desires to inhibit the format printout, bit 3 will be set high. The computer will execute a program to load the Memory Controlled Data Processor with a special walking bit pattern and place the system in a "Run" mode. The data will be recorded on tape for approximately four seconds. The system will stop. and the operator must type $X$ on the keyboard to terminate the tape and print the record of errors associated with the system test. Typing another $X$ on the keyboard will return the program to the diagnostic menu level (see Example 23).

\section{3 Tape Dump}

The tape dump option is entered by typing 3/CR on the keyboard. The operator may now enter the file number for the data tape placed on inachino 1 for playback. If the data tape is a nurinal dato tape, or a tape made from the diagnostic menus "Run MCP/MMF with Tape" options, the operator will place bit 2 of the data field on the Nova front panel in the duwn pocition. However, if the tape is an "error test" tape coming from the error detect format portion of the test routine, the operator will place bit 2 in the up position. 


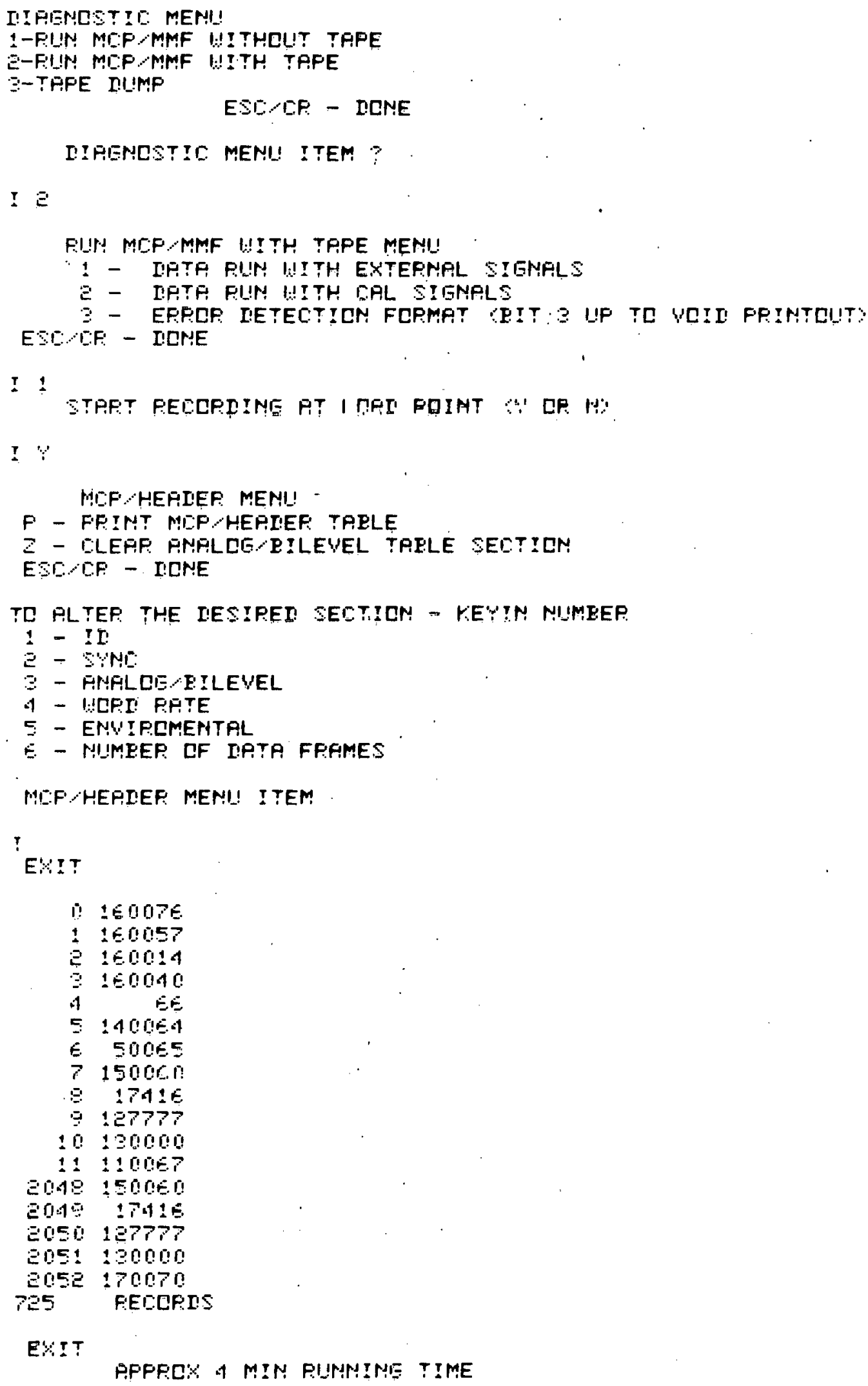


I!

FIIP NICF MMP IIITHCUT TPPE MENI

:-IRTP PILN UITH EXTEPNPL SIENALS

E-DPTP RUM UITH CPL SIENPLLS

Z-ERL FIUN UIITH EAL SIENALS

ESLOP - IECHE

I

I

ERL VALIIE =

: 226

IIIMP LFT IDN

1 - ME IIIMAF

E - DIMPP MEP DITPUTT

3 - IIUMP ECTH MCP FNI MMF

I $\Xi$

MCP HEPIER MEPIJ

F' - FFINT MICF MEEPIER TPELE

$z$ - CLEFR FNFILE $>$ EILEVEL TAELE SECTIDH

ESCOE - IDNE

TC PLTEF THE IESIPEL SECTICN - KEYIN NIMMPEF

1 - II

$2-5 Y M$

- PNPLLEREILEVEL

4 - IICFI FETE

5 - ENUIRCMENTPRL

E - NIIMEEF DF IITTP FPRMES

MTF HEFIER MENII ITEM

!

0 : 6000

$1 \quad 160057$

2160014

$3 \div 60040$

$4 \quad 56$

$5: 40001$

$5 \quad 5005$

$7 \pm 50000$

8 : $74 ! 5$

9 :อ7ร7\%

$\div 0 \div 0000$

$11: 1$ 10067

2049 150060

$204: 174: 6$

2050 127777

205: 100000

eose 170070

\pm PE 5 P

$\begin{array}{lll}13 & 65 & 41 \\ 35 & 48 & 42\end{array}$

3700

4040

E! $4 ! \quad 2$

$7 ?=0$

$\begin{array}{rr}14 & 40 \\ 14 & 41 \\ 45 & 60 \\ 0 & 0 \\ 52 & 43 \\ 43 & 56 \\ 0 & 0\end{array}$

$\begin{array}{rr}6 e & 50 \\ 2 & 43 \\ 0 & 0 \\ 16 & 6 ! \\ 12 & 12 \\ 10 & 77\end{array}$

43
50
70
73
46

42

43

48

$64 \quad 51$

0 16 E! Eर

$57 \quad 14$

4144

42 is:

Example E-22 
IIPENCSTIE: MEN!I! ITEM ?

I $\Xi$

FIIN MIF MMF UITH TPPE MENI!

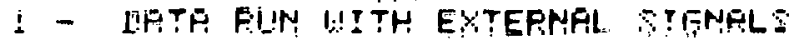

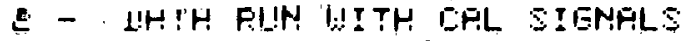

ESLEF - ICHE

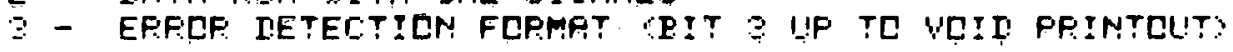

?

$0+50000$

1 !eogo!

E 10000

3 1e000

1 1 00004

5 : 60005

e 1erote

7 : 60007

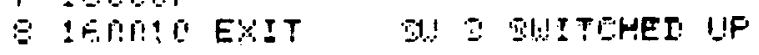

PI FECCRIS

ESIT

Example E-23 
With bit 2 in the down position, the operator will enter the record number, and the program will exit to dump the tape. To terminate the printout, the bit 1 switch is moved up. The computer will ultimately read the position of bit 1 and terminate the printout. When the printout is terminated, a new record number may be entered to order the system to print additional records as required by the operator (see Example 24).

With bit 2 in the up position, the tape must be an error detection format test tape. The operator selects the required record number, and the program exits to check for byte errors. Example 25 shows a printout from an error test tape, The printout will occur only when there is an error that has occurred some place in the data stream. If there are no errors in the record under test, the program will exit by printing 2000, and automatically read the next record.

Either of the two tape dump routines can be returned to select a new file number by typing ESC/CR to return to the diagnostic menu level. Typing 3/CR will allow the operator to enter a new file number for checking data in additional files. 
IIPENOSTIC MENU! ITEM ?

I

FILE PIIITEEE =-

TYFE K, CF EIT \& SULLF, TC EXIT?

EIT $Z$ SI, UIF FLP PUTE ERPCR CKS:

I!

FEIDEFI NUMHEER =

I

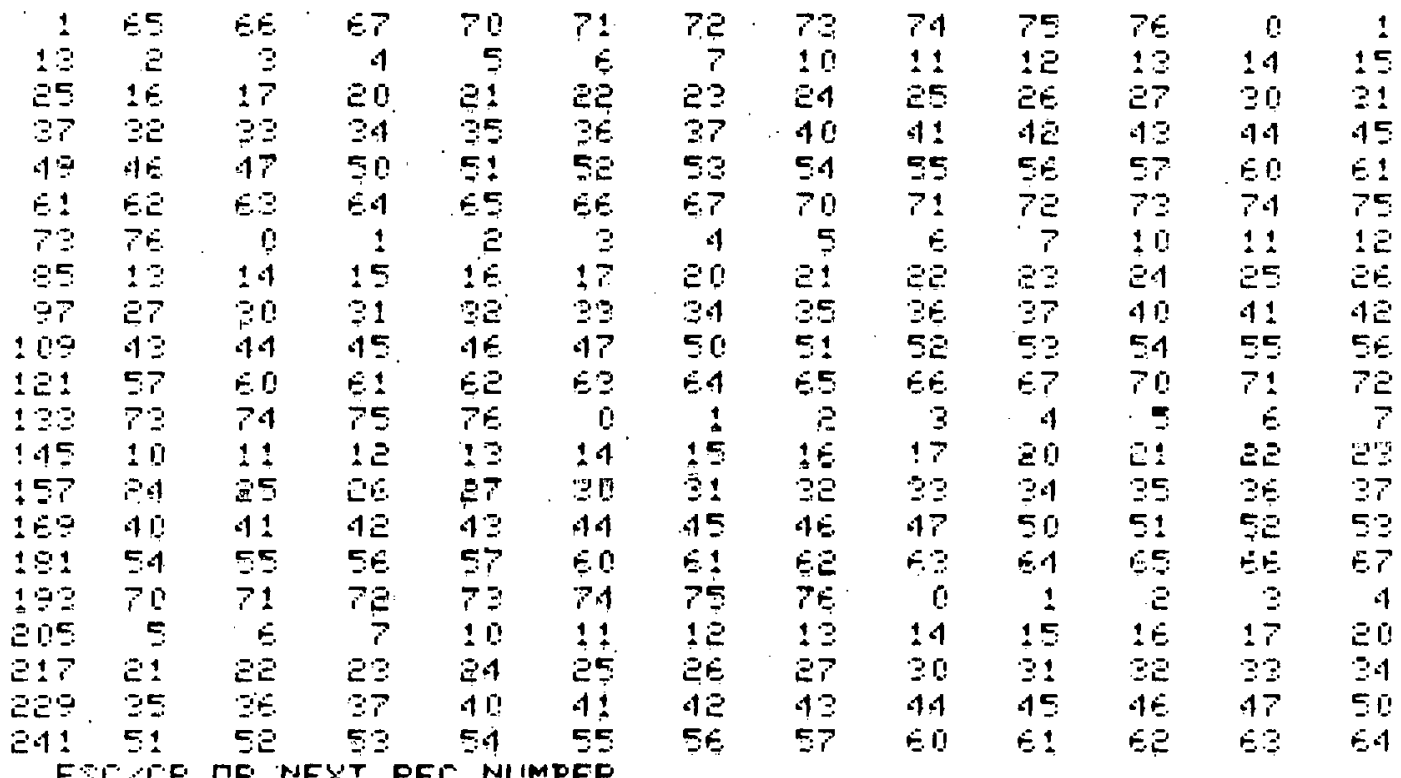

$!$

Example E-24 
I:THENCSTIE MER!I

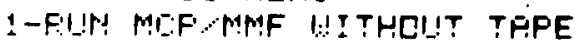

E-FILTS MEF MMF UITH TAPE

STPFE I!I!IMP

$$
\text { ESCOE: - RCHE }
$$

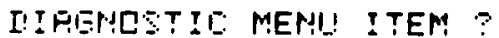

I :

FILE PIIMEER :=

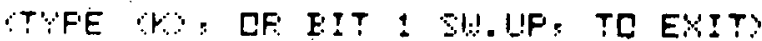

EIT $Z$ SI!. LIF FCF EYTE EPRCF EYS?

I :

FEELCFI MILMEEF =

T

\begin{tabular}{|c|c|c|c|c|c|c|c|c|c|c|c|}
\hline E000 & 1 & $\Xi$ & 27 & 10 & $4 !$ & 13 & 43 & 44 & 45 & $4 E$ & 47 \\
\hline 2000 & 10 & $4 !$ & 27 & 10 & $1 !$ & $4 \dot{2}$ & 13 & 41 & 45 & 15 & 17 \\
\hline 2000 & 0 & $!$ & 37 & 10 & $4 !$ & 40 & 42 & 44 & 45 & 45 & 47 \\
\hline 3000 & 37 & 40 & 27 & 10 & $4 !$ & 42 & 49 & 44 & 45 & 48 & 48 \\
\hline 1210 & $E Z$ & $E$ & $E E$ & $E$ & 5.4 & $E 5$ & 56 & $E 7$ & 70 & 71 & $P \Xi$ \\
\hline$=0100$ & 74 & 75 & 37 & 40 & $4 !$ & 12 & 43 & 44 & 45 & E & 47 \\
\hline E0100 & 34 & 35 & 37 & 90 & $4 !$ & $4 \Xi$ & 43 & 44 & 15 & 45 & 47 \\
\hline & 5 & 3 & 74 & 75 & $7 E$ & 0 & \pm & $\Xi$ & 5 & 1 & 5 \\
\hline 3000 & 30 & 31 & 27 & 40 & $4 !$ & 42 & 43 & 44 & 45 & 45 & 17 \\
\hline 3000 & 87 & 70 & 27 & 40 & $4 !$ & 4 & 42 & 44 & 45 & 45 & 17 \\
\hline 3000 & 27 & 20 & 27 & 90 & $4 !$ & $4 E$ & 42 & 14 & 45 & 45 & 47 \\
\hline 2000 & $E$ & $\therefore 7$ & 27 & 10 & $4 !$ & 12 & 43 & 44 & 45 & 48 & 17 \\
\hline 400 & 5 & $E$ & 67 & 70 & $7 !$ & $7 \Xi$ & 73 & 74 & 75 & $7 E$ & 1! \\
\hline 2000 & $E 5$ & $E \epsilon$ & 37 & 40 & 41 & 42 & 43 & 44 & 45 & $4 E$ & 47 \\
\hline$=000$ & $E 4$ & $E S$ & 37 & 40 & $4 !$ & 42 & 43 & 44 & 45 & 40 & 47 \\
\hline enon & 24 & 25 & 37 & 90 & $4 !$ & 43 & 43 & 44 & 45 & $4 E$ & 47 \\
\hline 2000 & 58 & 54 & 27 & 4.0 & $4 !$ & 42 & 42 & 41 & 45 & 15 & 47 \\
\hline$=000$ & 3 & $\Xi 4$ & 37 & 10 & $4 !$ & 12 & 42 & 44 & 45 & 4 & 47 \\
\hline Enoto & $E$ & $E$ & 37 & 10 & $4 !$ & 13 & 42 & 44 & 45 & E & 47 \\
\hline$=000$ & $\Xi z$ & 8 & 37 & 40 & $4 !$ & $4 E$ & 43 & 44 & 15 & 16 & 4 \\
\hline 3000 & $E !$ & $E$ & 27 & 10 & $4 !$ & $4 \overline{1}$ & 43 & 44 & 45 & S & 47 \\
\hline 3000 & $8 !$ & $\Xi E$ & 27 & 10 & $4 !$ & $A E$ & 43 & 44 & 15 & 45 & 47 \\
\hline 2000 & $E 0$ & $E !$ & 27 & 40 & $4 !$ & $4 \Xi$ & 43 & 44 & 45 & 16 & 47 \\
\hline 2000 & 20 & $\Xi 1$ & 27 & 40 & $4 !$ & बE & 42 & 14 & 45 & $1 E$ & 47 \\
\hline $1: 49$ & 50 & 56 & 57 & 50 & $5 !$ & $E Z$ & 82 & 54 & 55 & $E$ & $E$ \\
\hline 2000 & 56 & 57 & 28 & 40 & $4 !$ & $4 \Xi$ & 43 & 44 & 15 & AE & 47 \\
\hline 2000 & $1 E$ & 17 & 27 & 40 & $4 !$ & 43 & 43 & 4.4 & 45 & $4 E$ & 47 \\
\hline 2000 & 55 & $5 e$ & 37 & 40 & $4 !$ & 12 & 43 & 44 & 15 & $1 E$ & 47 \\
\hline E000! & 15 & !E & 37 & 10 & $4 !$ & $4 \Xi$ & 42 & 14 & 45 & & 47 \\
\hline 100 & 54 & 55 & 37 & 40 & $4:$ & $\sqrt{1 E}$ & 42 & 14 & 45 & 4 & הדם \\
\hline
\end{tabular}

ESTLF: CF: RIEXT FEE PIIMEER

Example E-25 


\section{0 Nova 2 Checkout Procedure}

The Nova 2 computer is tested using the Data General Diagnostic routines. A paper tape reader located in the bottom of the rack under the Nova is utilized to load diagnostic routines for the checkout of the Nova 2. The diagnostics on the paper tapes also are utilized to check the interface between the Silent 700 TTY and the Nova 2 computer. Consult the appropriate mamuals for instructions concerning these pieces of hardware and for the proper test steps in the checkout of the TTY and Nova 2.

The other diagnostic routines for checking the performance of the Pertec Digital Tape Machines and the Datum Magnetic Tape Controller Model 5091 are contained in the Datum peripheral equipment manual. There is a special diagnostic tape, labeled "AIDS Diagnostic", which has one rcmote and two program load routines for cherking tho porformailce uf the tape controllers. The software manul for the Model 5091 Maghetic Controller contains the instructions for utilizing this software on magnetic tape. 


\section{0 Calculations for the AIDS Format}

The AIDS data format is different from many data collection formats since it was designed to accomplish data compression by omitting samples. Figure 3 shows the format and the location of control words such as "Sync" and "End of Data Frame".

A form, which is at the end of this section, will assist the operator in determining several of the variables that must be entered into the program when the MCP header menu is programmed. The operator must examine the data channels to determine the highest data frequency that might be expected. This frequency, in Hertz, must be entered on line 1. (The operator should also determine that the low pass filters in the Analog Signal Conditioner will pass this frequency. If high frequency noise is expected about this frequency, the operator can adjust the low pass filter's cutoff frequency by changing the values of the components on the component modules associated with the signal conditioning amplifier in each data channel; this will eliminate some high frequency aliasing noise from the data.)

The operator should enter the number of samples per cycle on line 2. The minimum number is 2 samples per cycle based on theoretical considerations, with 5 samples per cycle belng a practical number to use in the calculations.

Multiplying line 1 by line 2 gives the number of samples per second per channel. 'This number is the number of data words that must be collected each second. Interspersed at equal intervals between the data words must be time and other information that is contained in the master frame. Since the time resolution must be at least. 1 second, there must be at least 10 master frames every second. The division by 10 or a larger number in line 4 calculations provides the proper time for the format. Calculations performed under line 5 will account for the channel codes that must be included in the format. Summing the totals on lines 6 and 7 gives the total number of words in a super frame and is entered in line 8.

Multiplying the number of words iin a supcr frame by the number of super frames that will occur in a second gives the word rate. This calculation is performed by multiplying the divisor used in line 4, which was 10 or a number greater than 10, by the number of words in a super frame.

Since only seven word rate values are given by the program, the operator must select the next higher rate available above the calculated word rate. This value is entered in line 10 : 
1. Highest frequency response expected for any data channel.

2. Samples per cycle ( 5 or more).

3. Multiply lines 1 and 2.

4. Divide the results of line 3 by 10 or more to determine number of data frames required. Division by 10 is based on minimum required to provide. $1 \mathrm{sec}$. time resulution. Round value to next higher integer. Number must bc less than 4095.

5. Determine number of format words

(a) Sync words. (Programmed for 4)

(b) Time code words.

(c) Word rate words.

(d) Environmental words. SADL 15 Rocky Flats 23

(e) Bilevel words $2 \times 5=$

(f) Six bit data channels $10 \times 2=$

(g) Six to twelve bit data channels $1 \times 3=$

(h) Master frame end worde

(i) Data frame end words

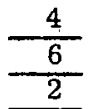

$\frac{\frac{15}{10}}{\frac{20}{3}} \frac{1}{\frac{1}{3}}$

6. Number of master frame words equals sum of $a, b, c$, $d, c, f, E$, aitul 1 .

7. Number of data frame words per super frame equals sum of $e, f, g$, and $i$, times line 4 .

8. Number of words per super frame equal sum of lines 6 and 7.

9. Multiple line 8 by divisor used in line 4 .

10. Select next highcr table rate. Maximum rate is 2,50 kilowordo.
$75 \mathrm{~Hz}$

\begin{tabular}{l}
5 samples/syslo \\
$\begin{array}{l}375 \text { samples/sec/ } \\
\text { channel }\end{array}$ \\
.38 number of data \\
\hline frames
\end{tabular}

61 M. F, words

1368 D. F. words

1429 words per super

14290 word rate

15. $625 \mathrm{kw}$ word rate 
1. Highest frequency response expected for any data channel.

$500 \mathrm{~Hz}$

2. Samples per cycle ( 5 or more).

3. Multiply line 1 times line 2.

4. Divide the results of line 3 by 10 or more to determine number of data frames required. Division by 10 is based on minimum required to provide . $1 \mathrm{sec}$. time resolution. Round value to next higher integer. Number must be less than 4095 .

5. Determine number of format words,

(a) Sync words. (Programmed for 4)

(b) Time code words,

(c) Word rate words.

(d) Environmental words. SADL 15 Rocky Flats $23 \quad 15$

(e) Bilevel words $2 \times 5=$

(f) Six bit data channels $10 \times 2=$

(g) Six to twelve bit data channels $\times 3$

(h) Master frame end words

(i) Data frame end words

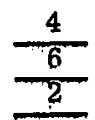

$\frac{1}{3}$

6. Number of master frame words equals sum of $a, b, c$, $d, e, f, g$, and $h$.

$58 \mathrm{M}$. F. words

7. Number of data frame words per super frame equals sum of $e, f, g$, and $i$ times line 4 .

8250 D. F. words

8. Number of words per super frame equal sum of lines 6 and 7.

8308 words per super frame

9. Multiply line 8 by divisor used in line 4 .

83080 word rate

10. Select next higher table rate. Maximum rate is 250 kilowords.

250 number of data

frames 


\section{DISTRIBUTION:}

1754 C. S. Johnson (3)

1739 J. D. Williams (2)

9420 T. L. Pace

9421 M. J. Navratil

9421 N. E. Corlis (10)

8266 E. A. Aas

3141 C. A. Pepmueller (Actg) (5)

3151 W. L. Garner (3)

DOE/TIC (25)

For DOE/TIC (Unlimițed Release)

(R. P. Campbell, 3172-3) 